Article

\title{
Inertia Provision and Small Signal Stability Analysis of a Wind-Power Generation System Using Phase-Locked Synchronized Equation
}

\author{
Yifei Wang ${ }^{1,2, *}$ and Youxin Yuan ${ }^{1}$ \\ 1 School of Automation, Wuhan University of Technology, No. 205 Luoshi Rd., Wuhan 430070, China; \\ yuanyouxinwhut@163.com \\ 2 Intelligent Transportation System Program, University of Wisconsin-Madison, 1415 Engineering Drive, \\ Madison, WI 53706, USA \\ * Correspondence: wzf6608@whut.edu.cn
}

Received: 23 January 2019; Accepted: 1 March 2019; Published: 6 March 2019

\begin{abstract}
The inertia and damping of the modern power system are consistently decreased when wind energy has a high penetration level into the grid. This paper proposes a novel solution through transforming the wind turbine generator into an equivalent motion equation mimicking the basic characteristics of the synchronous generator (SG). This synchronized equation builds upon the phase-locked loop (PLL) model of the doubly-fed induction generator (DFIG), which characterizes the inertia constant, damping coefficient, and synchronizing torque. Thanks to this work, the dynamic performance of the inverter-based asynchronous generator could be analyzed from the perspective of the classical rotor motion equation. It further enables us to employ the analogy method to provide the DFIG with automated frequency response ability and to estimate the inertia constant quantitatively. Results also manifest that based on the synchronized equation, the PLL forms a power system stabilizer to enhance the power system oscillation. Hence, parameters tuning in PLL for coordinating inertia provision and damping enhancement are introduced. The contribution of this study lies in that the equivalent synchronized equation is established to optimize the system operation without alterations in the existing control structure of the DFIG. The theoretical analysis and the strategy are verified through the power system simulator.
\end{abstract}

Keywords: doubly-fed induction generator; phase-locked loop; swing equation; analogy; inertia provision; power system small signal stability; parameter optimization

\section{Introduction}

The wind power generation system offers solutions to energy shortage and environmental contamination with the effective application of the clean, abundant, ever-renewable wind energy [1]. The globally installed wind power capacity has reached up to 539 GW since 2017 [2], which significantly reduces the dependency on fossil energy and greenhouse gas emissions. Among the current wind power technology, the doubly-fed induction generator (DFIG) based wind power generation system presents obvious dominance with high energy transfer efficiency, flexible grid connection, and power decoupling control [3-5]. Nevertheless, the power system with high wind energy penetration experiences significant transitions in dynamic and transient characteristics [6]. Different from the synchronous generators (SGs), the DFIG operates at the maximum power producing point for a given wind speed [7]. For this reason, the system frequency is decoupled from the partially rated power converter, which results in a loss of ability in the DFIG to provide inertia and frequency support $[8,9]$. The reduced inertia has also presented challenges to the system small signal stability $[10,11]$. This paper aims to improve both the inertia and oscillation damping of the power grid. 
Inertia provision strategies are basically classified into three types: the virtual inertia control (VIC), the virtual synchronous generator (VSG) technology, and the phase-locked loop (PLL)-based inertia emulation method. (i) The VIC introduces the frequency deviation into the active power controller and employs the stored energy to suppress frequency drops [12]. The basic controller for VIC includes the droop control [13], the differential control [14], and the proportional plus derivative control [15]. In addition, the inertia emulation strategy by switching the maximum power point tracking (MPPT) curve is proposed to improve the robustness of the controller [16]. In [17], an enhanced frequency support technique was proposed utilizing the superconducting magnetic energy storage (SMES) preserved in the permanent magnet synchronous generator (PMSG). The fast response ability of SMES provides the PMSG with higher inertia provision and less stress in the rotational mass. In addition to inertia emulation, the impacts of VIC on the small signal stability of the power system were analyzed in $[18,19]$. Under receiving and feeding networks, the VIC may either improve the oscillation damping or produce negative damping for the power grid. (ii) The VSG technology controls the inverter-based renewable energy sources to mimic the essential behavior of the SG [20]. Provided with the virtual inertia and the frequency droop control, the VSG takes the same responsibility to attenuate the power imbalance as the SG does. Aiming at the system small signal stability with the application of the VSG, the parameters design of the power loop is explored to analyze and improve the stability margin [21,22]. Superior to the VIC, the VSG technology is equipped with the damping and reactive power control to suppress the power oscillation. However, more complex inverter control algorithms and fault current limiting schemes are required for the VSG. (iii) The PLL-based inertia emulation method adopts the controlled delay lock technology, which provides the wind turbine generator (WTG) with the automated frequency response ability [23]. The current researches have calculated the inertia time constant of WTG with the frequency-domain expression [24,25]. Meanwhile, the separate effect of the PLL parameter on the small signal stability of the power system has been studied [26,27]. The existing research findings illustrate that the inertia of WTG could be enhanced by decreasing the parameters in PLL with a constant ratio [23]. However, this approach only ensures that the internal stability of PLL remains unchanged [27]. Based on the previous researches, this paper focuses on improving both the inertia and damping through changing the phased-locked mechanism in PLL.

The PLL-based inertia emulation has a number of advantages compared with the VIC and VSG in that (i) the parameters tuning in PLL makes the DFIG respond to frequency disturbance spontaneously without alterations or modifications in the existing active power control loop; (ii) the standard and technologies for the existing PLL-based voltage-source converter are quite mature; and (iii) the equivalent motion equation is established based on the phase-locked mechanism, so that the DFIG responds to the frequency excursion in the same way as the SG does. Therefore, the inertia time constant of the DFIG has physical significance and could be quantified.

However, modification of parameters in PLL is likely to have a significant impact on the system damping and locking accuracy of PLL. The unresolved issues for the PLL-based inertia emulation also include establishing the equivalent swing equation of WTG to reveal its motion mechanism, obtaining the time-domain expression of the inertia time constant of WTG to estimate precisely its inertial response ability, and clarifying synthetic effects of PLL parameters on small signal stability of the power system. Aiming at these problems, this paper derives the time-domain expression of inertia constant of the DFIG by establishing the PLL-synchronized swing equation. The inertia emulation and parameters optimization strategy are proposed to realize better frequency response performance and high oscillation damping of the power system at the same time.

Section 2 "Materials and Methods" is organized as follows: In Section 2.1, the synchronized swing equation of the DFIG is established based on the PLL model. In Section 2.2, the physical significance of the equivalent inertia is discussed, and the inertia emulation strategy is proposed though parameters tuning. In Section 2.3, the internal stability of PLL and its impacts on the global stability of the multi-machine system are analyzed in detail. The parameters optimization strategy 
is proposed to improve the inertial response ability of the DFIG while maintaining strong oscillation damping. In Section 3 "Simulation Results", the mechanisms analysis and the strategy are verified through the simulations in Power System Simulator for Engineering (PSS/E).

\section{Materials and Methods}

The description of the variables used through the text is listed as follows:

$K_{\mathrm{P}_{-} \mathrm{PLL}}, K_{\mathrm{I} \_\mathrm{PLL}}$
$u_{\mathrm{ds}}, u_{\mathrm{qs}}$
$i_{\mathrm{ds}}, i_{\mathrm{qs}}$
$\delta_{\mathrm{pll}}, \omega_{\mathrm{pll}}$
$\delta_{\mathrm{g}}, \omega_{\mathrm{g}}$
$\delta_{\mathrm{w}}, \theta_{\mathrm{in}}$
$U_{\mathrm{w}}, E, U$
$H_{\mathrm{w}}, H_{\mathrm{g}}$
$D_{\mathrm{w}}, D_{\mathrm{g}}$
$P_{\mathrm{w}}, P_{\mathrm{g}}$
$s_{\mathrm{r}}, \omega_{0}$

Proportional plus integral (PI) control parameters of PLL. Stator voltage in the dq reference frame. Stator current in the dq reference frame.

Phase angle of PLL, phase-locked angular velocity.

Power angle of SG, rotor angular velocity of SG.

Phase angle of stator voltage, relative phase angle between $U_{\mathbf{w}}$ and $E$.

Stator voltage vector, internal voltage vector, voltage of infinite bus. Inertia time constant of wind power plant (WPP), inertia time constant of SG.

Damping coefficient of WPP, damping coefficient of SG.

Active power output of WPP, active power output of SG.

Slip ratio of DFIG, reference angular velocity of the power system.

\subsection{Establishment of PLL-Synchronized Swing Equation of the DFIG}

\subsubsection{Introduction of the DFIG Control Structure}

This section aims to introduce the control structure of the doubly-fed induction generator (DFIG). As is shown in Figure 1, the control structure of the DFIG is composed of the physical model and the control model [23]. The physical model includes the aerodynamic, shaft, and generator models. The control model includes the pitch angle control, maximum power point tracking, speed control, and the converter control models. According to [28], the specific differential equations of the physical models and the control models of the DFIG have been studied in detail. In addition, the phase-locked loop (PLL) model is utilized to track the voltage angle and frequency in the point of common coupling (PCC). The PLL model forms an important basis for the voltage-oriented control, the power-decoupling control, and the constant-frequency operation of the DFIG. However, the mechanisms of the PLL model on output characteristics of the DFIG have not been studied fully.

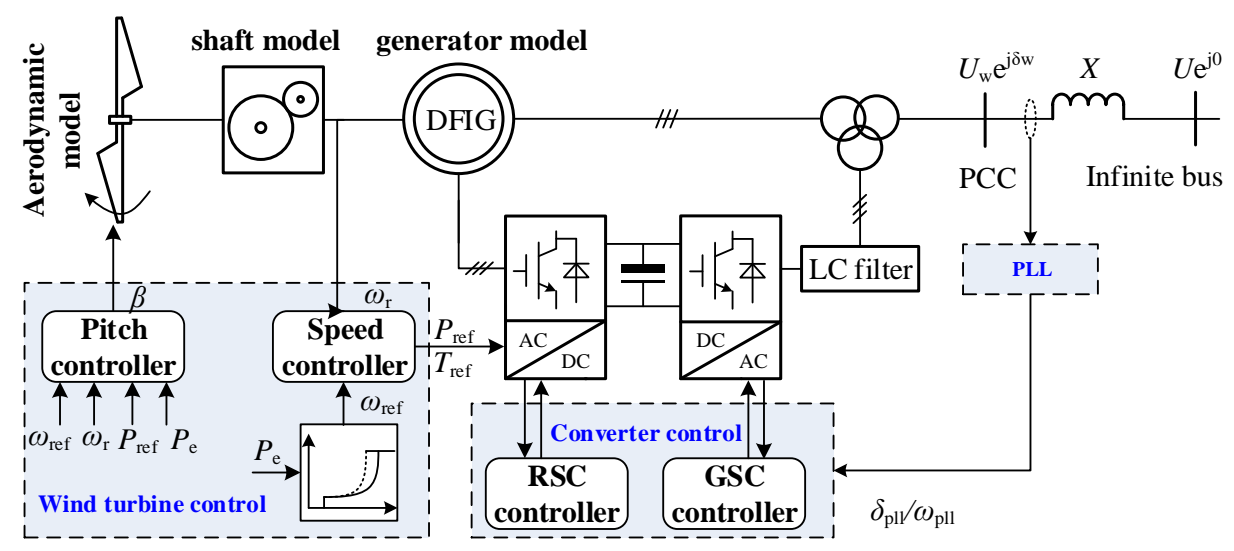

Figure 1. Structure diagram of the doubly-fed induction generator (DFIG) integrated into the infinite bus system.

This paper focuses on the mechanisms of the PLL model alone on the output characteristics of the DFIG. According to [23], the active power increments of the DFIG are determined by two parts: the active power control loop and the PLL control loop, which are shown in Figure 2. The active power control loop produces the internal phase angle increment $\Delta \theta_{\text {in }}$. Whereas the PLL control loop produces the phase-locked angle increment $\Delta \delta_{\text {pll }}$. The sum of $\Delta \theta_{\text {in }}$ and $\Delta \delta_{\text {pll }}$ constitutes the synthetic power 
angle variation $\Delta \delta_{\text {in }}$, which directly influences the active power output of the DFIG. The dynamics of the active power control loop is neglected to highlight the effects of the PLL model. Therefore, there is $\Delta \theta_{\text {in }}=0$ and $\Delta \delta_{\text {pll }}=\Delta \delta_{\text {in }}$ in this paper.

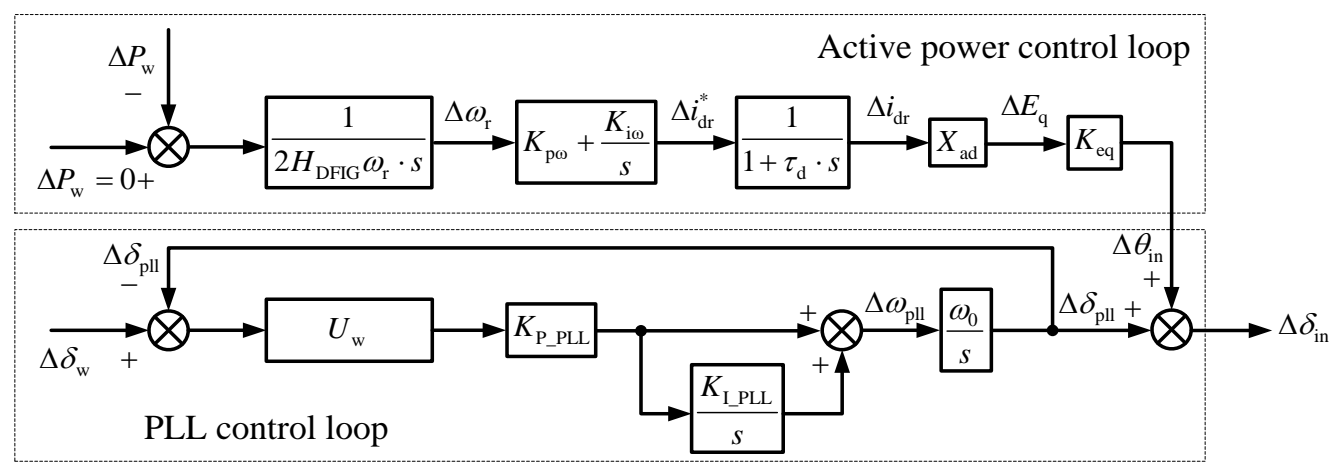

Figure 2. Transfer function block diagram of the active power control model and phase-locked loop (PLL) model.

Generally, the PLL model consists of an integration element $1 / s$ and a proportional plus integral (PI) control. Figure 2 shows the transfer function block diagram of the PLL model in PSS/E [29]. Accordingly, the differential equation of the PLL model is expressed as [26]:

$$
\frac{1}{\omega_{0}} \dot{\delta}_{\mathrm{pll}}=\omega_{\mathrm{pll}}=K_{\mathrm{I} \_\mathrm{PLL}} \cdot K_{\mathrm{P} \_\mathrm{PLL}} x_{\mathrm{pll}}-K_{\mathrm{P} \_\mathrm{PLL}} u_{\mathrm{ds}}
$$

As is shown in (1) and Figure 2, $\delta_{\text {pll }}$ is the phase-locked angle; $\dot{\delta}_{\text {pll }}$ is the first-order derivative of $\delta_{\mathrm{pll}}, \omega_{\mathrm{pll}}$ is the phase-locked angular velocity; $\omega_{0}=2 \pi f_{0}$ is the reference angular velocity of the power system; $K_{\text {P_PLL }}$ and $K_{I_{-} P L L}$ are the proportional gain and integral gain, respectively; $x_{\mathrm{pll}}$ is the intermediate state variable and satisfies $\dot{x}_{\mathrm{pll}}=-u_{\mathrm{ds}}$, and $u_{\mathrm{ds}}$ denotes the d-axis stator voltage amplitude.

\subsubsection{Establishment of Swing Equation of the DFIG Based on PLL}

According to [30], the rotor motion equation of SG could be regarded as a modified PLL, which ensures the synchronous operation between the SG and the power system. Based on this, this section attempts to derive the equivalent swing equation of the DFIG based on the PLL equation in (1). Basically, the PLL model measures the voltage phase angle at PCC to realize voltage-oriented control. As is shown in Figure 3, the voltage vector $\boldsymbol{U}_{\mathbf{w}}$ at PCC locates in the dq synchronous reference frame, and the dq-axis stator voltage vectors $u_{\mathrm{ds}}$ and $u_{\mathrm{qs}}$ locate in the dq PLL reference frame, respectively [24]. The $\mathrm{d}\left(\omega_{\mathrm{pll}}\right)$-axis and $\mathrm{q}\left(\omega_{\mathrm{pll}}\right)$-axis rotate with the angular velocity of $\omega_{\mathrm{pll}}$, and the $\mathrm{q}\left(\omega_{0}\right)$-axis and $\mathrm{d}\left(\omega_{0}\right)$-axis rotate with the angular velocity of $\omega_{0} . \delta_{\mathrm{w}}$ is the initial phase angle of $\boldsymbol{U}_{\mathrm{w}}$, and $\delta_{\text {pll }}$ is also the initial phase angle of $\boldsymbol{u}_{\mathrm{qs}} . \boldsymbol{E}$ is the internal voltage vector of the DFIG. $\theta_{\text {in }}$ is the angle difference between $\boldsymbol{E}$ and $\boldsymbol{u}_{\mathrm{qs}}$. 


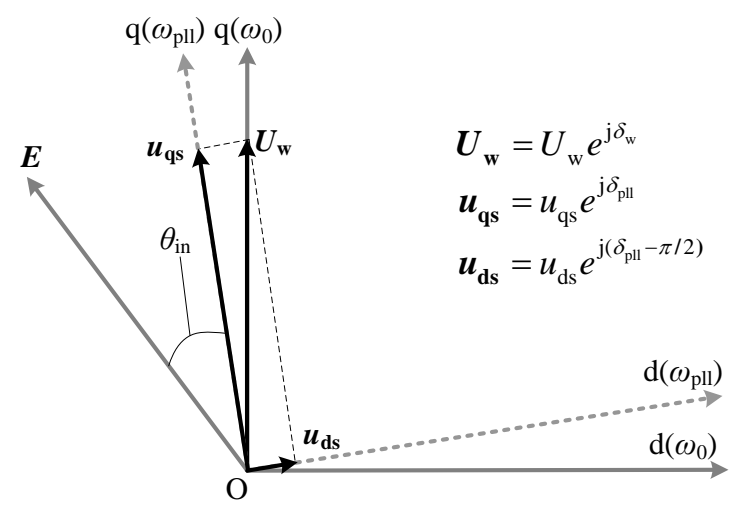

Figure 3. Voltage vectors in dq PLL reference frame and dq synchronous reference frame.

According to Figure 3, the voltage amplitudes of $\boldsymbol{u}_{\mathrm{qs}}$ and $\boldsymbol{u}_{\mathrm{ds}}$ are expressed as [31]:

$$
\left\{\begin{array}{l}
u_{\mathrm{ds}}=U_{\mathrm{w}} \sin \left(\delta_{\mathrm{pll}}-\delta_{\mathrm{w}}\right) \\
u_{\mathrm{qs}}=U_{\mathrm{w}} \cos \left(\delta_{\mathrm{pll}}-\delta_{\mathrm{w}}\right)
\end{array}\right.
$$

In the steady state, $u_{\mathrm{qs}}$ coincides with $\boldsymbol{U}_{\mathrm{w}}$ based on the voltage-oriented control. Therefore, $u_{\mathrm{ds}}=0$, $u_{\mathrm{qs}}=U_{\mathrm{w}}$, and $\delta_{\mathrm{w}}-\delta_{\mathrm{pll}}=0$. In the following analysis, $\delta_{\mathrm{w}}$ and $\delta_{\mathrm{pll}}$ denote their initial values whereas $\Delta \delta_{\mathrm{w}}$ and $\Delta \delta_{\mathrm{pll}}$ denote their variations.

During the dynamic process, however, the variations of the voltage phase angle are produced (represented by $\Delta \delta_{\mathrm{w}}$ and $\left.\Delta \delta_{\mathrm{pll}}\right)$. Hence, $\boldsymbol{u}_{\mathrm{qs}}$, and $\boldsymbol{u}_{\mathrm{ds}}$ locate on the $\mathrm{q}\left(\omega_{\mathrm{pll}}\right)$-axis and $\mathrm{d}\left(\omega_{\mathrm{pll}}\right)$-axis, respectively. The increment equations of $u_{\mathrm{qs}}$, and $u_{\mathrm{ds}}$ are calculated as:

$$
\left\{\begin{array}{l}
\Delta u_{\mathrm{ds}}=U_{\mathrm{w}} \cos \left(\delta_{\mathrm{pll}}-\delta_{\mathrm{w}}\right) \Delta \delta_{\mathrm{pll}}-U_{\mathrm{w}} \cos \left(\delta_{\mathrm{pll}}-\delta_{\mathrm{w}}\right) \Delta \delta_{\mathrm{w}}=U_{\mathrm{w}}\left(\Delta \delta_{\mathrm{pll}}-\Delta \delta_{\mathrm{w}}\right) \\
\Delta u_{\mathrm{qs}}=-U_{\mathrm{w}} \sin \left(\delta_{\mathrm{pll}}-\delta_{\mathrm{w}}\right) \Delta \delta_{\mathrm{pll}}+U_{\mathrm{w}} \sin \left(\delta_{\mathrm{pll}}-\delta_{\mathrm{w}}\right) \Delta \delta_{\mathrm{w}}=0
\end{array}\right.
$$

Furthermore, the active power output of the DFIG is expressed as [32]:

$$
P_{\mathrm{w}} \approx\left(1-s_{\mathrm{r}}\right)\left(u_{\mathrm{ds}} i_{\mathrm{ds}}+u_{\mathrm{qs}} i_{\mathrm{qs}}\right)
$$

where $s_{\mathrm{r}}$ is the slip ratio; $i_{\mathrm{ds}}$ is the $\mathrm{d}$-axis stator current; $i_{\mathrm{qs}}$ is the q-axis stator current. Neglecting the dynamic variations of $s_{\mathrm{r}}, i_{\mathrm{ds}}$, and $i_{\mathrm{qs}}$, the increment equation of $P_{\mathrm{w}}$ is expressed as:

$$
\Delta P_{\mathrm{w}} \approx\left(1-s_{\mathrm{r}}\right)\left(\Delta u_{\mathrm{ds}} i_{\mathrm{ds}}+\Delta u_{\mathrm{qs}} i_{\mathrm{qs}}\right)=\left(1-s_{\mathrm{r}}\right) \Delta u_{\mathrm{ds}} i_{\mathrm{ds}}
$$

According to (1), the intermediate state variable $x_{\mathrm{pll}}$ is represented by $-u_{\mathrm{ds}} / s$ ( $s$ is the Laplacian operator), so the increment equation of PLL in (1) is calculated as:

$$
\Delta \omega_{\mathrm{pll}}=-K_{\mathrm{I} \_\mathrm{PLL}} K_{\mathrm{P} \_\mathrm{PLL}} \frac{\Delta u_{\mathrm{ds}}}{s}-K_{\mathrm{P} \_\mathrm{PLL}} \Delta u_{\mathrm{ds}}
$$

As is indicated in (5) and (6), $\Delta u_{\mathrm{ds}}$ establishes the relationship between the active power equation and the PLL equation. The expression of $\Delta u_{\mathrm{ds}}$ is calculated as $\Delta u_{\mathrm{ds}}=-\Delta \omega_{\mathrm{pll}} /\left(K_{\mathrm{P} \_\mathrm{PLL}}\right.$ $+K_{\text {I_PLL }} K_{P_{-} \text {PLL }} / s$ ), which is substituted into (5) to obtain the transfer function of PLL. In addition, the equivalent transformations are implemented to make the transfer function of PLL have the same mathematical form as the swing equation:

$$
\left(-\Delta P_{\mathrm{w}}-\frac{\Delta P_{\mathrm{W}}}{\Delta \delta_{\mathrm{pll}}} \cdot \frac{\omega_{0}}{K_{\mathrm{I} \_\mathrm{PLL}}} \cdot \Delta \omega_{\mathrm{pll}}\right) \cdot \frac{K_{\mathrm{I} \_\mathrm{PLL}} K_{\mathrm{P} \_\mathrm{PLL}}}{\left(1-s_{\mathrm{r}}\right) i_{\mathrm{ds}} \cdot s}=\Delta \omega_{\mathrm{pll}}=\frac{s}{\omega_{0}} \Delta \delta_{\mathrm{pll}}
$$


where $\Delta P_{\mathrm{w}} / \Delta \delta_{\mathrm{pll}}$ denotes the synchronizing torque of the DFIG. In this paper, $\Delta P_{\mathrm{w}} / \Delta \delta_{\mathrm{pll}}$ is defined as $T_{\mathrm{s}}$. The block diagram of the transfer function of (7) is illustrated in Figure 4a. The block diagram of the transfer function of the rotor motion equation of the SG is also illustrated in Figure $4 \mathrm{~b}$ [33] for comparison.

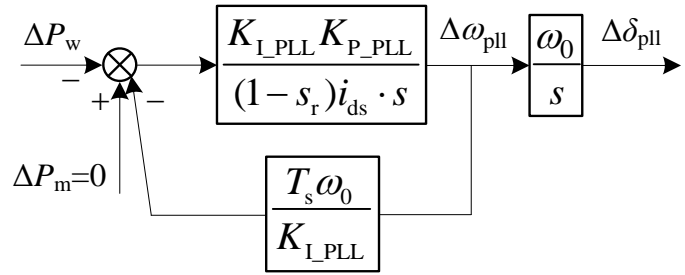

(a)

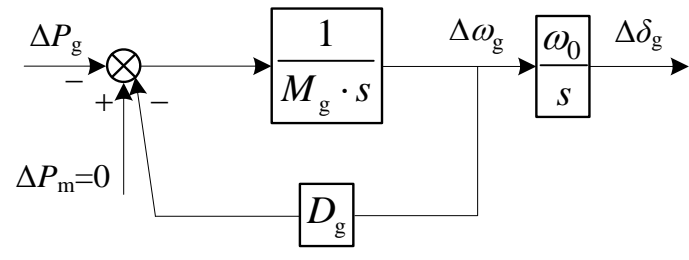

(b)

Figure 4. Transfer function block diagram of classical swing equations: (a) Equivalent swing equation of the DFIG based on PLL model; (b) Swing equation of the synchronous generator (SG) based on rotor motion equation.

Accordingly, the transfer function in (7) could also be written in the form of the differential equation:

$$
M_{\mathrm{w}} \Delta \ddot{\delta}_{\mathrm{pll}}=-\Delta P_{\mathrm{w}}-D_{\mathrm{w}} \Delta \omega_{\mathrm{pll}}, \text { where } M_{\mathrm{w}}=\frac{\left(1-s_{\mathrm{r}}\right) i_{\mathrm{ds}}}{K_{\mathrm{I} \_ \text {PLL }} K_{\mathrm{P} \_ \text {PLL }} \omega_{0}}, D_{\mathrm{w}}=\frac{T_{\mathrm{s}} \omega_{0}}{K_{\mathrm{I} \_ \text {PLL }}}
$$

where $\ddot{\delta}_{\text {pll }}$ is the second-order derivative of $\delta_{\text {pll }}$.

Comparing the transfer function of the DFIG in Figure 4a with the transfer function of the SG in Figure $4 \mathrm{~b}$, it could reasonably conclude that $D_{\mathrm{w}}$ corresponds to the damping coefficient $D_{\mathrm{g}}$, whereas $M_{\mathrm{w}}$ corresponds to the inertia constant $M_{\mathrm{g}}$. In addition, $\delta_{\mathrm{pll}}$ and $\omega_{\mathrm{pll}}$ are the state variables, which have the same dynamic characteristics as the rotor angle $\delta_{\mathrm{g}}$ and the rotor speed $\omega_{\mathrm{g}}$ of the SG. Therefore, Equation (8) is defined as the swing equation of the DFIG, which is established on the PLL model, the active power equation, and the voltage-oriented control from (1) to (5). According to (8), the swing equation of the DFIG has the same components with the rotor motion equation, including the inertia constant, the damping coefficient, the synchronizing torque, and the power angle. In the next sections, the physical significance of the model will be explained further, and the accuracy of the model will be verified in the simulations of inertia provision and damping analysis.

\subsection{Inertia Provisions Using the PLL-Synchronized the DFIG Model}

\subsubsection{Physical Significance of the Proposed Swing Equation of the DFIG}

It is well known that the decoupling between the converter controls of the DFIG and system frequency results in no inertia response of the DFIG. The PLL model, however, produces the phase angle variations of $\Delta \delta_{\mathrm{w}}-\Delta \delta_{\text {pll }}$ between the internal voltage vector $E$ and the voltage vector $U_{\mathrm{w}}$ at PCC, which changes the output characteristics of the DFIG during the dynamic process. According to Figure $3, \mathrm{q}\left(\omega_{\mathrm{pll}}\right)$-axis coincides with $\mathrm{q}\left(\omega_{0}\right)$-axis, and $\boldsymbol{E}$ has the same angular velocity with $U_{\mathrm{w}}$ in the steady state. However, under the frequency step down scenario, for instance, the PLL cannot accurately lock the grid voltage angle in real-time. $\mathrm{Q}\left(\omega_{0}\right)$ will lag behind $\mathrm{q}\left(\omega_{\mathrm{pll}}\right)$ due to the decrease in system frequency. The angle difference between $E$ and $U_{\mathbf{w}}$ increases from $\theta_{\text {in }}$ to $\theta_{\text {in }}+\Delta \delta_{\mathrm{w}}-\Delta \delta_{\text {pll }}$. The increase of phase angle difference contributes to the increase of active power output of the DFIG. Consequently, the PLL provides the DFIG with the ability to respond to the frequency disturbance. The response capability for frequency excursion is described by the inertia constant in (8). 


\subsubsection{Inertia Emulation Using the PLL-Synchronized Swing Equation}

Note that the typical values of PLL parameters are $K_{P \_P L L}=40$ and $K_{\text {I_PLL }}=100$ [27]. According to (8), the value of $M_{\mathrm{W}}$ is small enough to be neglected under typical values, which explains why the DFIG could not respond to the frequency excursion under the general state. If both of $K_{P \_P L L}$ and $K_{\mathrm{I} \_P L L}$ decrease, $M_{\mathrm{W}}$ will increase, and the inertial response ability for the DFIG will be enhanced.

Based on the inertia expression in (8) and the DFIG model in Figure 1, Figure 5 shows the variation surface of inertia time constant $H_{\mathrm{w}}\left(2 H_{\mathrm{w}} / \omega_{0}=M_{\mathrm{w}}\right)$ with $K_{\mathrm{P} \_ \text {PLL }}$ and $K_{\mathrm{I} \_P L L}$. The system parameters refer to Appendix A. According to Figure 5, if $K_{\mathrm{P}_{-} \mathrm{PLL}}$ or $K_{\mathrm{I}_{\mathrm{P}} \mathrm{PLL}}$ is larger than 5, $H_{\mathrm{W}}$ approaches to 0 . Whereas if both of $K_{\mathrm{P} \_P L L}$ and $K_{\mathrm{I} \_P L L}$ decrease to smaller than $5, H_{\mathrm{w}}$ increases rapidly. Therefore, the DFIG has a sufficient inertia response ability only when both $K_{P_{-} P L L}$ and $K_{I_{Z} P L L}$ are small enough. This result offers the possibility for improving the inertia provision of the DFIG just by changing the parameters in PLL.

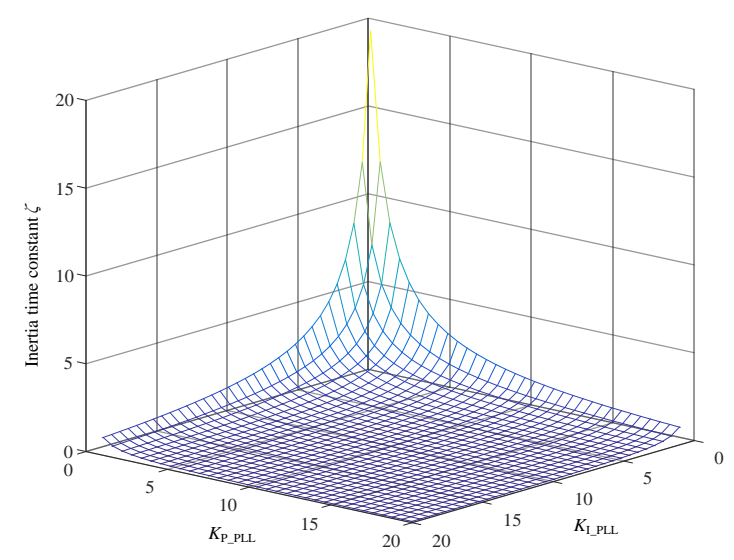

Figure 5. Variation of inertia time constant of the DFIG with $K_{P_{-} P L L}$ and $K_{I_{-}}$PLL in the infinite bus system.

The inertia provision strategy based on PLL has many unique advantages compared with the virtual inertia control, such as (i) emulating the kinetic characteristics of the rotor rotational mass based on the physical model of the swing equation, which provides the DFIG with the same inertia response characteristics with the SG; (ii) enabling us to obtain the quantitative expression of the inertia time constant of the DFIG; (iii) without changing the control structure nor adding more control loops in the DFIG. However, changing $K_{P_{-} P L L}$ and $K_{I_{-} P L L}$ might also result in adverse effects, including low locking accuracy of PLL and weak oscillation damping. The following parts focus on the impacts of $K_{\text {P_PLL }}$ and $K_{I_{-} P L L}$ on the small signal stability of the power system, and research on the parameters tuning for coordination between the inertia provisions and damping enhancement.

\subsection{Small Signal Stability Analysis Using PLL-synchronized Swing Equation}

\subsubsection{Internal Stability of PLL Model}

The single-DFIG infinite bus system could be employed to analyze the internal stability of the PLL-synchronized swing equation. Based on the single-DFIG infinite bus system in Figure 1, this part focuses on the impacts of $K_{P_{-} P L L}$ and $K_{I_{-} P L L}$ on the locking accuracy and the internal stability of PLL. According to Figure 1, the active power increment $\Delta P_{\mathrm{w}}$ is calculated as in (9) according to the active power balance equation [16].

$$
\Delta P_{\mathrm{w}}=\frac{U_{\mathrm{w}} U \cos \delta_{\mathrm{pll}}}{X} \cdot f \cdot \Delta \delta_{\mathrm{pll}}=T_{\mathrm{s}} \cdot \Delta \delta_{\mathrm{pll}}, \quad \text { where } \quad f=\frac{\left(1-s_{\mathrm{r}}\right) i_{\mathrm{ds}}}{\left(1-s_{\mathrm{r}}\right) i_{\mathrm{ds}}+U \cos \delta_{\mathrm{w}} / X}
$$


where $U$ is the voltage amplitude in the infinite bus, $U_{\mathrm{w}}$ is the voltage amplitude at PCC, $X$ is the reactance of the transmission line, and the resistance is neglected.

The complete differential equation of the single-DFIG infinite bus system is obtained by combining (8) and (9). Solving the corresponding characteristic equation, the damping ratio $\xi$ and the response time $t_{\mathrm{r}}$ [34] of PLL are expressed as $\left(\omega_{0}=1\right)$ :

$$
\begin{gathered}
\xi=\frac{D_{\mathrm{w}}}{2 \sqrt{T_{\mathrm{s}} M_{\mathrm{w}}}}=\sqrt{\frac{T_{\mathrm{s}} K_{\mathrm{P} \_ \text {PLL }}}{4\left(1-s_{\mathrm{r}}\right) i_{\mathrm{ds}} K_{\mathrm{I}_{-} \mathrm{PLL}}}} \\
t_{\mathrm{r}} \propto \frac{2\left(1-s_{\mathrm{r}}\right) i_{\mathrm{ds}}}{T_{\mathrm{s}} K_{\mathrm{P} \_\mathrm{PLL}}}
\end{gathered}
$$

According to (10), the damping ratio $\xi$ is proportional to $K_{\mathrm{P}_{-} \mathrm{PLL}}$, whereas inversely proportional to $K_{I_{-} P L L}$. Note that the damping ratio $\xi$ is proportional to $K_{P_{-} P L L} / K_{I_{-} P L L}$. To improve the inertial response ability of the DFIG, $K_{P_{-} P L L}$ and $K_{I_{-} P L L}$ could be set as small enough values but maintain the same ratio $\left(K_{I_{\perp} P L L} / K_{P_{-} P L L}=100 / 40\right)$. In this case, the damping properties of PLL would not change.

As is indicated in (11), the response time $t_{\mathrm{r}}$ is inversely proportional to $K_{\mathrm{P}_{-} \mathrm{PLL}}$. The increase of $t_{\mathrm{r}}$ means that it takes more time for PLL to lock the system voltage angle and frequency. Therefore, the decrease of $K_{P_{-} P L L}$ improves the inertial response ability of the DFIG, but slows down the response rate and reduces the locking accuracy of PLL at the same time.

\subsubsection{Small Signal Stability of Wind-Integrated Power System}

This section analyzes the impacts of the PLL-synchronized swing equation of the DFIG on global stability of the multi-machine power system. As is shown in Figure 6, the single-machine infinite bus system integrated with a DFIG-based wind farm is served as the test model. The system parameters refer to Appendix A. Since the PLL-synchronized swing equation of the DFIG is established resembling the conventional SG, the system is composed of two swing equations with the same structure. If $\Delta \delta_{\mathrm{S}}$ $=\Delta \delta_{\mathrm{g}}-\Delta \delta_{\text {pll }}$ is defined as the synthetic power angle of the system, the simultaneous differential equation of the system could be established by subtracting the swing equation of the DFIG from that of the SG.

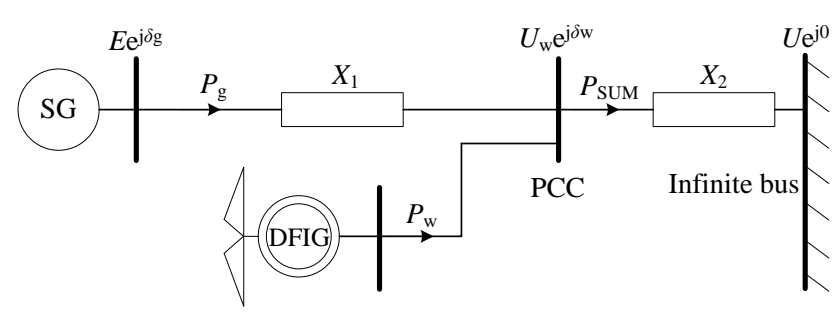

Figure 6. Simplified circuit diagram of the DFIG integrated into the single-machine infinite bus system.

In the two-machine infinite bus system in Figure 6, the swing equation of the SG is expressed as in (12) where $\Delta P_{\mathrm{g}}$ is derived from the active power balance equation [16]:

$$
\Delta \ddot{\delta}_{\mathrm{g}}+\frac{D_{\mathrm{g}}}{M_{\mathrm{g}}} \Delta \dot{\delta}_{\mathrm{g}}+\frac{\Delta P_{\mathrm{g}}}{M_{\mathrm{g}}}=0, \quad \Delta P_{\mathrm{g}}=\frac{E U_{\mathrm{w}} \cos \left(\delta_{\mathrm{g}}-\delta_{\mathrm{w}}\right)}{X_{1}} f\left(\Delta \delta_{\mathrm{g}}-\Delta \delta_{\mathrm{pll}}\right)
$$

In the same way, the swing equation of the DFIG is expressed as in (13) where $\Delta P_{\mathrm{g}}$ is also derived from the active power balance equation [16].

$$
\Delta \ddot{\delta}_{\mathrm{pll}}+\frac{D_{\mathrm{w}}}{M_{\mathrm{w}}} \Delta \dot{\delta}_{\mathrm{pll}}+\frac{\Delta P_{\mathrm{w}}}{M_{\mathrm{w}}}=0, \quad \Delta P_{\mathrm{w}}=\frac{U_{\mathrm{w}} E \cos \left(\delta_{\mathrm{w}}-\delta_{\mathrm{g}}\right)}{X_{1}} f\left(\Delta \delta_{\mathrm{pll}}-\Delta \delta_{\mathrm{g}}\right)
$$


where $\delta_{\mathrm{g}}, D_{\mathrm{g}}$, and $M_{\mathrm{g}}$ are the rotor angle, the damping coefficient, and the inertia constant of the SG, respectively; $\ddot{\delta}_{\mathrm{g}}$ and $\dot{\delta}_{\mathrm{g}}$ are the second-order and first-order derivatives of $\delta_{\mathrm{g}}$, respectively; $X_{1}$ is the reactance between the SG and DFIG; and $X_{2}$ is the reactance of the transmission line between the PCC and the infinite bus. If the transmission power on $X_{2}$ reaches its total transfer capacity (TTC), the coefficient $f$ satisfies $f \approx\left(1-s_{\mathrm{r}}\right) \cdot i_{\mathrm{ds}} /\left[E \cos \left(\delta_{\mathrm{g}}-\delta_{\mathrm{w}}\right) / X_{1}+\left(1-s_{\mathrm{r}}\right) \cdot i_{\mathrm{ds}}\right]$.

It is assumed that the system has uniform damping: $D_{\mathrm{g}} / M_{\mathrm{g}} \approx D_{\mathrm{w}} / M_{\mathrm{w}}$. This assumption is reasonable especially for small values of $K_{P_{-} P L L}$ and $K_{I_{-} P L L}$ and for two large power grids interconnected with long distance transmission lines. Based on the swing equations of the DFIG and SG, the simultaneous differential equation of the system is obtained by subtracting (13) from (12):

$$
\Delta \ddot{\delta}_{\mathrm{s}}+\frac{1}{2}\left(\frac{D_{\mathrm{g}}}{M_{\mathrm{g}}}+\frac{D_{\mathrm{w}}}{M_{\mathrm{w}}}\right) \Delta \dot{\delta}_{\mathrm{s}}+\left(\frac{M_{\mathrm{g}}+M_{\mathrm{w}}}{M_{\mathrm{g}} M_{\mathrm{w}}}\right) \frac{E U_{\mathrm{w}} \cos \left(\delta_{\mathrm{g}}-\delta_{\mathrm{w}}\right)}{X_{1}} f \Delta \delta_{\mathrm{s}}=0
$$

Equation (14) is employed to analyze the damping properties of the multi-machine power system. The differences between (14) and (8) are that (14) embodies the interactive influences between the DFIG and SG, whereas Equation (8) only reflects the internal stability of PLL. Through solving the characteristic equation of (14), the damping ratio is expressed as:

$$
\xi=\frac{1}{4}\left(\frac{D_{\mathrm{g}}}{M_{\mathrm{g}}}+\frac{D_{\mathrm{w}}}{M_{\mathrm{w}}}\right) / \sqrt{\left(\frac{1}{M_{\mathrm{g}}}+\frac{1}{M_{\mathrm{w}}}\right) \frac{E U_{\mathrm{w}} \cos \left(\delta_{\mathrm{g}}-\delta_{\mathrm{w}}\right) f}{X_{1}}}
$$

To analyze the impacts of $K_{\text {I_PLL }}$ and $K_{\text {P_PLL }}$ on the small signal stability of the two-machine infinite bus system, the variations of eigenvalues and damping ratios with $K_{I_{-} P L L}$ and $K_{P \_P L L}$ are illustrated in Figure 7a,b, respectively.

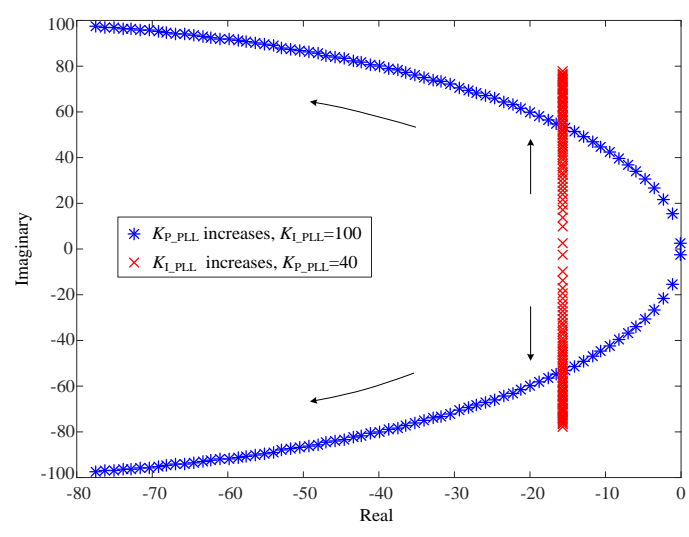

(a)

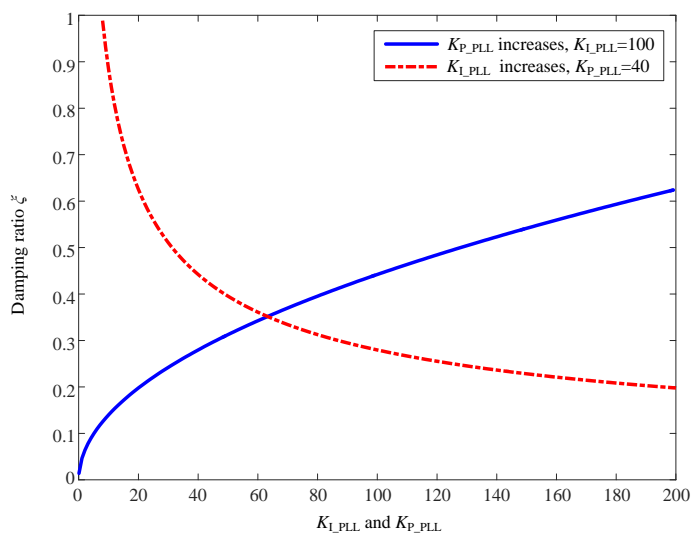

(b)

Figure 7. Eigenvalue analysis of the single-machine infinite bus system integrated with a wind farm: (a) Variation of eigenvalues with $K_{\mathrm{P} \_P L L}$ and $K_{\mathrm{I} \_P L L} ;(\mathbf{b})$ Variation of damping ratio with $K_{\mathrm{P} \_P L L}$ and $K_{\mathrm{I} \_P L L}$.

According to Figure $7 \mathrm{a}$, the real parts of the eigenvalues move away from the original point when $K_{P_{-} P L L}$ increases, whereas the real parts are not affected by $K_{I_{L} P L L}$. According to Figure $7 \mathrm{~b}$, the damping ratios increase when $K_{P_{-} P L L}$ increase, whereas decrease when $K_{I_{L} P L L}$ increase. Therefore, the PLL-based swing equation of the DFIG might deteriorate the small signal stability of the system with large $K_{\text {I_PLL }}$ and small $K_{\text {P_PLL }}$.

As is discussed in Section 2.3.1, the internal stability of the PLL would not change if $K_{\text {I_PLL }}$ and $K_{P_{-} P L L}$ decrease with a constant $K_{I_{-} P L L} / K_{P_{-} P L L}$ ratio. As for the global stability of the multi-machine system, the combined effects of $K_{I_{-} P L L}$ and $K_{P_{-} P L L}$ should be analyzed further. 
According to (15), the damping ratio of the multi-machine power system is not merely relative to $K_{I_{-} P L L} / K_{P_{-} P L L}$. For ease of analysis, the damping ratio of (15) is rewritten as:

$$
\xi=\frac{a K_{\text {P_PLL }}}{\sqrt{b+c K_{\text {P_PLL }} K_{\text {I_PLL }}}}=\sqrt{\frac{a}{\frac{b}{K_{\mathrm{P}_{-} \mathrm{PLL}}^{2}}+c \frac{K_{\mathrm{I} \_\mathrm{PLL}}}{K_{\mathrm{P} \_ \text {PLL }}}}}
$$

where $a=\frac{1}{2} \frac{T_{\mathrm{s}}}{i_{\mathrm{ds}}\left(1-S_{\mathrm{r}}\right)}, b=\frac{E U_{\mathrm{w}} \cos \left(\delta_{\mathrm{g}}-\delta_{\mathrm{w}}\right) f}{M_{\mathrm{g}} X_{1}}, c=\frac{E U_{\mathrm{w}} \cos \left(\delta_{\mathrm{g}}-\delta_{\mathrm{w}}\right) f}{i_{\mathrm{ds}}\left(1-S_{\mathrm{r}}\right) X_{1}}$.

As is indicated in (16), if $K_{I_{-} P L L}$ and $K_{P_{-} P L L}$ are large enough, $b / K_{P_{-} P L L}^{2}$ is small enough to be neglected compared with $c K_{I_{-} P L L} / K_{P_{-} P L L}$. In this condition, the damping ratio $\xi$ remains nearly unchanged when $K_{I_{-} P L L}$ and $K_{P_{-} P L L}$ decrease with a constant $K_{I_{-} P L L} / K_{P_{-} P L L}$ ratio. Whereas if $K_{P \_P L L}$ and $K_{I_{-} P L L}$ are small enough, $b / K_{P_{-} P L L}^{2}$ is comparable with $c K_{I_{-} P L L} / K_{P_{-} P L L}$ and cannot be neglected. In this case, the damping ratio $\xi$ decreases with the decrease of $K_{P_{-} P L L}$ even if $K_{I_{-} P L L} / K_{P_{-} P L L}=$ constant.

Figure 8 describes the variation surface of damping ratios with $K_{I_{-} P L L}$ and $K_{P_{-} P L L}$ in the two-machine infinite bus system. The same conclusions could be drawn that the damping ratio decreases when $K_{I_{-} P L L}$ increases and $K_{P_{-} P L L}$ decreases. When $K_{P_{-} P L L}$ is small enough, $\xi$ is down to nearly zero even if $K_{\mathrm{I}_{-} \mathrm{PLL}} / K_{\mathrm{P} \_\mathrm{PLL}}=$ constant. The decrease of $K_{\mathrm{I}_{-} \mathrm{PLL}}$ and $K_{\mathrm{P} \_ \text {PLL }}$ with the same ratio for improving the inertial response ability of the DFIG, however, would eventually deteriorate the system damping.

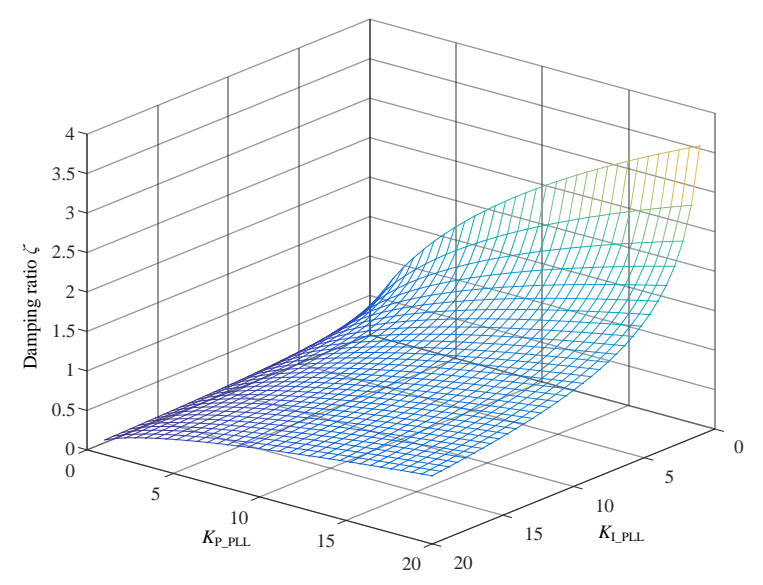

Figure 8. Variation surface of damping ratios with $K_{\text {I_PLL }}$ and $K_{\text {P_PLL. }}$

\subsubsection{Parameters Optimization for Damping Enhancement and Inertia Provision}

In fact, if $K_{I_{-} P L L}$ and $K_{\text {P_PLL }}$ are tuned properly, a large inertia time constant and an ideal damping ratio could be realized at the same time. This section proposes three principles for parameters optimization of PLL to solve the contradiction between inertial provisions and damping reduction caused by the decreases of $K_{I_{-} P L L}$ and $K_{P_{-} P L L}$.

Figure $9 \mathrm{a}, \mathrm{b}$ illustrate the variation curves of inertia time constants and damping ratios under different ratio of $k=K_{I_{-} P L L} / K_{P_{-} P L L}(k$ is set as $0.2,0.4,0.6,0.8,1.0,1.2,1.4,1.6,1.8$, and 2.0, respectively). The decrease of $K_{P_{-} P L L}$ decreases the system damping even if $K_{I_{\perp} P L L} / K_{P_{-} P L L}=$ constant. In addition, the decrease of $K_{P_{-} P L L}$ also reduces the locking accuracy of PLL according to Section 2.3.1. Thus, the first principle for the parameters tuning in PLL is that $K_{P_{-} P L L}$ should not be too small, to decrease the steady-state error of PLL and avoid system instability. 


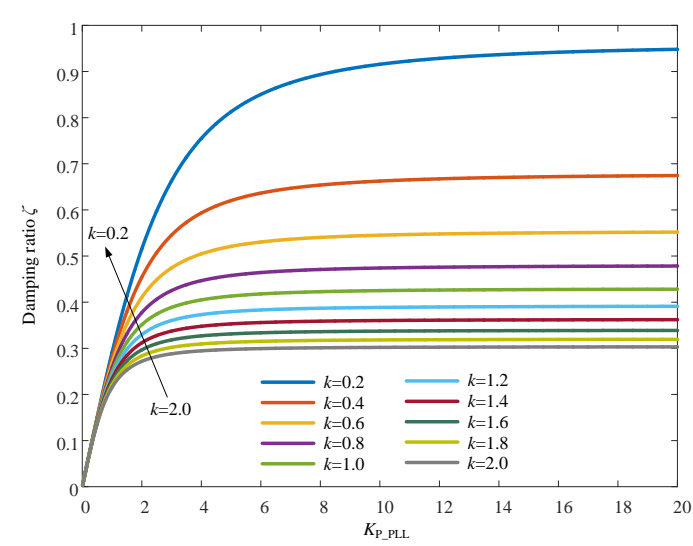

(a)

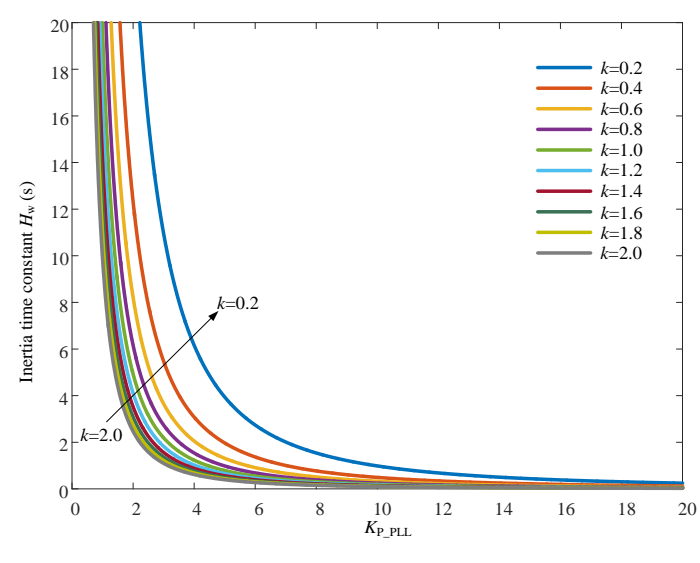

(b)

Figure 9. Small signal stability analysis and inertia time constant calculation when $K_{\mathrm{I} \_P L L}$ and $K_{\mathrm{P} \_P L L}$ decrease with the constant ratio $k\left(k=K_{I_{-} P L L} / K_{P_{-} P L L}\right.$ and $k$ varies within 0.2-2.0): (a) Variations of damping ratios with $K_{\mathrm{P}_{-} \mathrm{PLL}} ;(\mathbf{b})$ Variations of inertia time constants with $K_{\mathrm{P}_{-} \mathrm{PLL}}$.

Fortunately, the decrease of $K_{\text {I_PLL }}$ (corresponded with the smaller $k$ in Figure 9) could improve both of system damping and inertial response ability of the DFIG simultaneously. Furthermore, $K_{\text {I_PLL }}$ has no effects on the response rate of PLL according to (11). Therefore, the second principle for the parameters tuning in PLL is that the ratio of $K_{\mathrm{I}_{-} P L L}$ to $K_{\mathrm{P}_{-} \mathrm{PLL}}$ is set as small as possible. This principle brings out three benefits: (i) improving the response rate of PLL (increasing $K_{P_{-} P L L}$ ); (ii) damping enhancement (increasing $K_{P_{-} P L L}$ and decreasing $K_{I_{-} P L L}$ ), and (iii) sufficient inertial provisions (decreasing $K_{\text {I_PLL }}$ ).

The third principle for parameters tuning in PLL is based on the performance requirements of the power system. The requirements are that wind power plants (WPPs) should respond to the frequency, which is equivalent to at least $2 \mathrm{~s}$ of inertia time constant [35], and the damping ratio of the system should be higher than 0.4 [34]. If $K_{P_{-} P L L}$ and $K_{I_{-} P L L}$ are tuned properly based on the principles above, acceptable damping and sufficient inertia response ability could be realized at the same time. Taking the variation curves of $H_{\mathrm{w}}$ and $\xi$ with $k=0.2$ in Figure 9 for example, if $K_{P_{-} P L L}$ is set as 4 and $K_{I_{-} P L L}$ is set as 0.8 , the inertia time constant of $H_{\mathrm{w}}$ is larger than $6 \mathrm{~s}$, and the damping ratio is not lower than 0.7 .

The main steps for parameters tuning are shown in Figure 10. For a certain power system integrated with WPPs, the first step is to calculate the power flow of the whole system. Based on this, the active power increments of both wind farms $\Delta P_{\mathrm{w}}$ and SGs $\Delta P_{\mathrm{g}}$ are obtained with the power balance equation. The second step is to estimate the equivalent inertia time constant $H_{\mathrm{w}}$ and damping coefficient $D_{\mathrm{w}}$ of the wind farm according to $(8) . H_{\mathrm{w}}, D_{\mathrm{w}}$, and $\Delta P_{\mathrm{w}}$ constitute the basic elements of swing equation of the WPP in (13). Accordingly, the simultaneous differential equation of the whole system is established by subtracting the swing equation of the WPP from that of the SG, which is implemented as described in (14). Solving the characteristic equation, the eigenvalues and the damping ratio are obtained, which are strongly correlated to $K_{P_{-} P L L}$ and $K_{I_{-} P L L}$ according to (16). Therefore, the three principles for parameters tuning in PLL are introduced to ensure that the inertia time constant of the WPP is larger than $2 \mathrm{~s}$ and the damping ratio of the whole system is not lower than 0.4. Eventually, the parameters optimization in the PLL-synchronized swing equation offers better frequency recovery performance and higher damping capacity for the power system. 


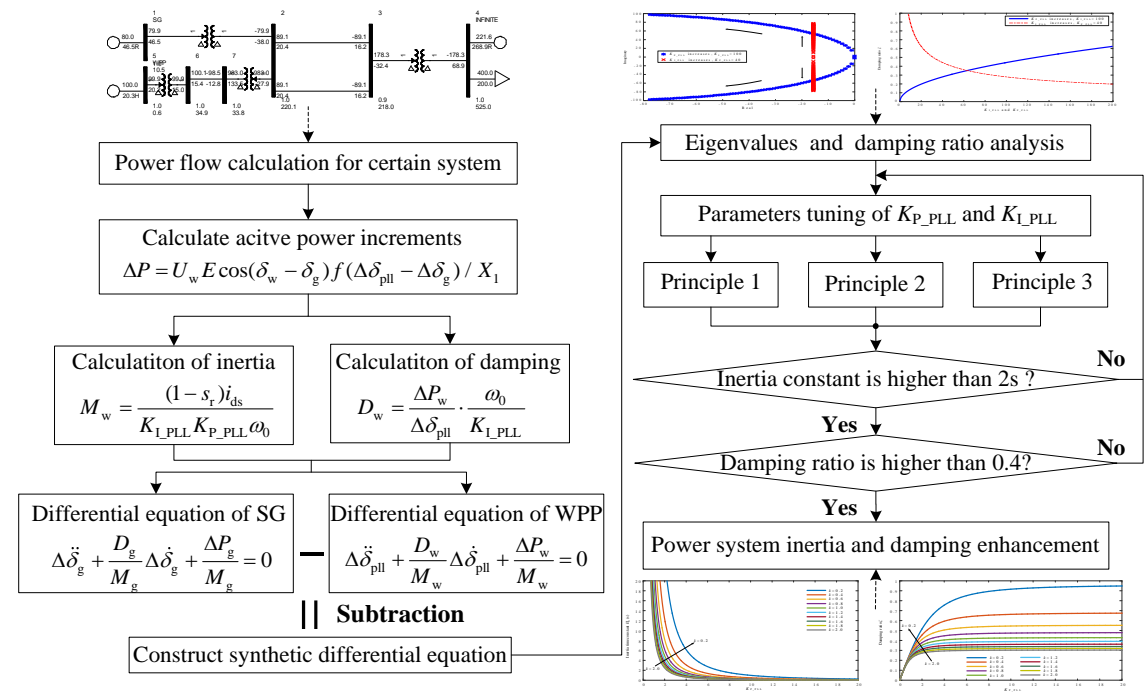

Figure 10. Flowchart for the steps of parameters tuning in PLL.

\section{Simulation Results}

Based on the analysis above, the DFIG is provided with sufficient inertial response ability with proper parameters tuning in PLL. Meanwhile, the proportional gain and integral gain have different impacts on the system damping and should be set following certain principles. For this work, the time domain simulations in PSS/E are conducted to verify (i) the frequency response ability of the DFIG with different $K_{I_{-} P L L}$ and $K_{P_{-} P L L}$ (ii) the variation of the system damping with different $K_{\text {I_PLL }}$ and $K_{P_{-} P L L}$, and (iii) the effectiveness of parameters optimization for $K_{I_{-} P L L}$ and $K_{P_{-} P L L}$.

\subsection{Simulations in Single-Machine Infinite Bus System With a WPP}

This section simulates the impacts of $K_{\text {I_PLL }}$ and $K_{\text {P_PLL }}$ on the inertial response ability of the DFIG and the system damping in the single-machine infinite bus system integrated with a wind power plant (WPP). As is shown in Figure 11, the WPP on Bus 5, which consists of 67 unit 1.5 MW DFIG, is integrated into the single-machine infinite bus system through the two-stage transformer. The DFIG is represented by the generic WT3 model in PSS/E. It is assumed that each DFIG in the WPP has the same output characteristics, so the WPP is equivalent to a single wind turbine generator with the sum of the capacity of each DFIG unit. The synchronous generator on Bus 1 is represented by the round rotor generator model, whereas the synchronous generator on the infinite Bus 4 is represented by the classical generator model. The reference capacity of the system is $100 \mathrm{MVA}$, and the load power is 400 MW. The penetration rate of wind power is $24.94 \%$. The power flow data of the system is shown in the circuit diagram in Figure 11, and the model parameters refer to the [29].

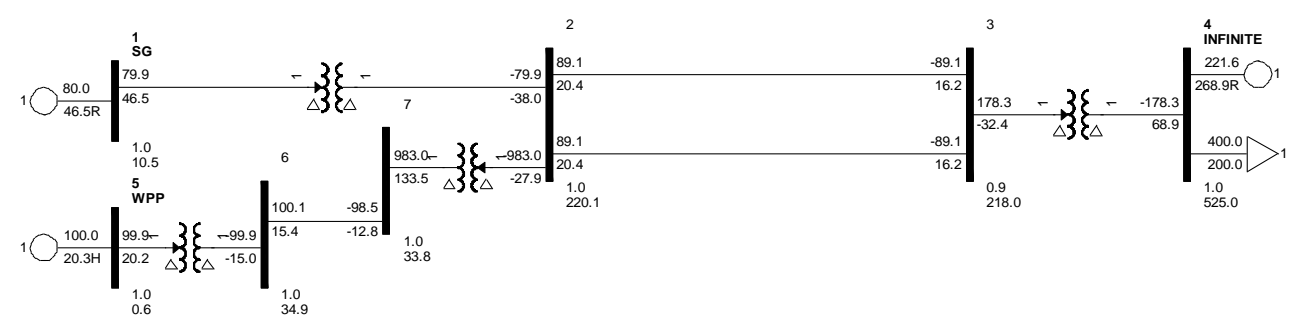

Figure 11. Circuit diagram and power flow solution of the single-machine infinite bus system integrated with a wind power plant (WPP).

Based on this wind-integrated power system, five cases are conducted, that is: case 1 tests the influences of $K_{P_{-} P L L}$ on inertial responses, case 2 tests the influences of $K_{I_{-} P L L}$ on inertia responses, case3 tests the influences of $K_{P_{-} P L L}$ on system damping, case 4 tests the influence of $K_{I_{-} P L L}$ on system 
damping, and case 5 tests the joint effects of $K_{I_{-} P L L}$ and $K_{P_{-} P L L}$ on system damping. The fault scenarios in case 1 and case 2 are set as the active load on Bus 4 decreasing from 400MW to 350MW at $10 \mathrm{~s}$. The fault scenarios in case3-case 5 are set as a three-phase short circuit fault occurring at Bus 3 at $10 \mathrm{~s}$ and being cleared after $0.1 \mathrm{~s}$.

In case1, $K_{I_{-} P L L}$ is set as five and $K_{P_{-} P L L}$ is set as $6,10,15$, and 25 respectively. Figure $12 \mathrm{a}-\mathrm{c}$ show the time domain waveforms of the active power of the WPP, rotor speed of the WPP, and the system frequency. According to Figure 12a, the instantaneous active power increment at $10 \mathrm{~s}$ manifests that the WPP could respond to frequency fluctuation after the parameters tuning of PLL. In addition, the amplitude of active power increases with the decrease of $K_{P \_P L L}$, which indicates that the decrease of $K_{\text {P_PLL }}$ improves the inertial response ability. As shown in Figure $12 b$, the declines of the rotor speed of the WPP at the initial stage of frequency excursion is due to the utilization of the kinetic energy of the wind turbine rotor. The smaller value of $K_{\mathrm{P} \_} \mathrm{PLL}$ is, the deeper the decline of rotor speed is. The active power increment from the WPP eases the active power imbalance of system, and inhibits the declines of system frequency, as is shown in Figure 12c.

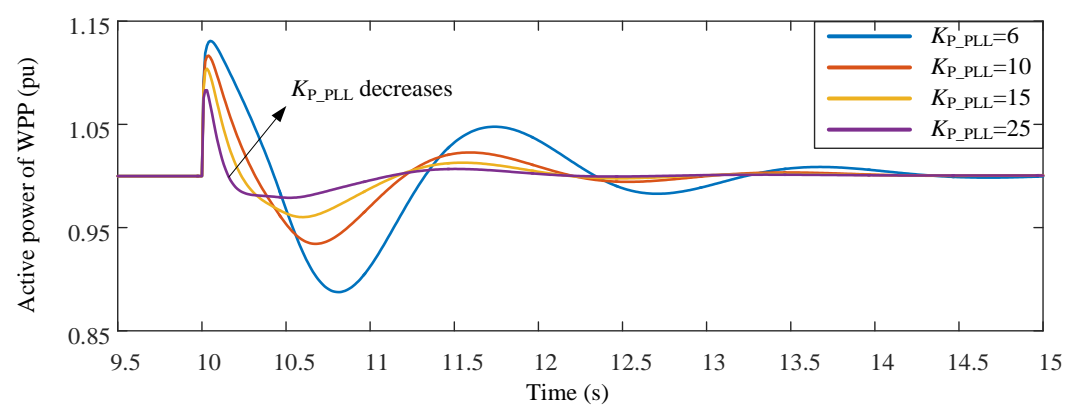

(a)

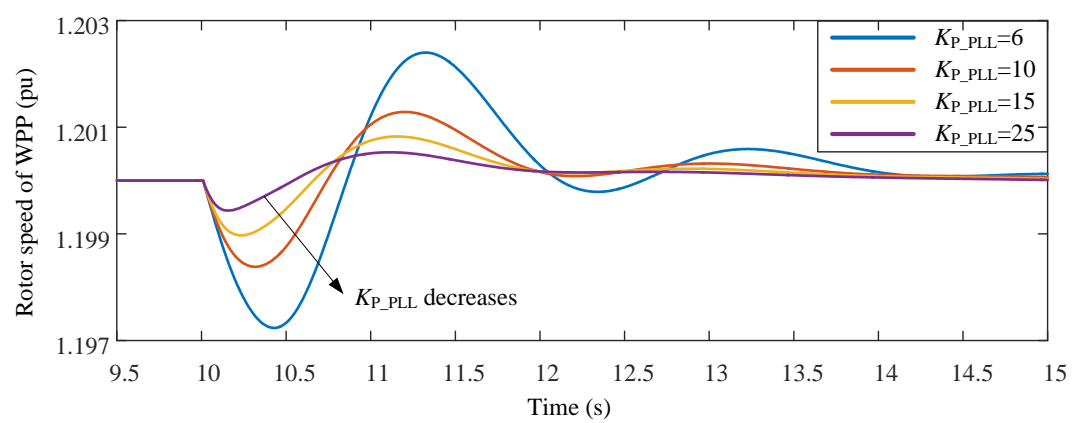

(b)

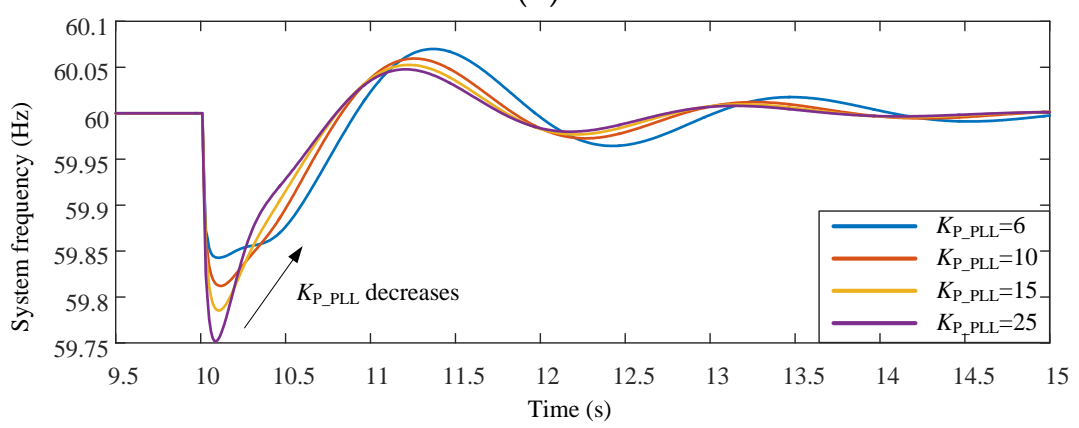

(c)

Figure 12. Case1: response curves of the WPP with different $K_{\mathrm{P} \_P L L}\left(K_{\mathrm{I} \_P L L}=5\right)$ under the disturbance of load reduction for inertia emulations: (a) Active power of the WPP; (b) Rotor speed deviation of the WPP; (c) System frequency.

In case2, $K_{P_{-} P L L}$ is set as 4 and $K_{I_{-} P L L}$ is set as $10,20,30$, and 50 respectively. Figure 13a-c show the variations of the active power of the WPP, rotor speed of the WPP, and system frequency. 
Figure 13a indicates that the decrease of $K_{\text {I_PLL }}$ increases both the amplitude and duration of active power supporting of the WPP. Note that the additional energy produced from the WPP is the product of active power and time. More additional energy contributed to the system results in more utilization of kinetic energy from the rotating mass of the turbine blades. Thus, the rotor speed of the WPP declines with a decrease of $K_{\mathrm{I} \_P L}$, as shown in Figure 13b. According to Figure 13c, with lower values of $K_{I_{-} P L L}$, more additional active power from the WPP is produced to alleviate the power shortage in the system, which inhibits the declines of system frequency.

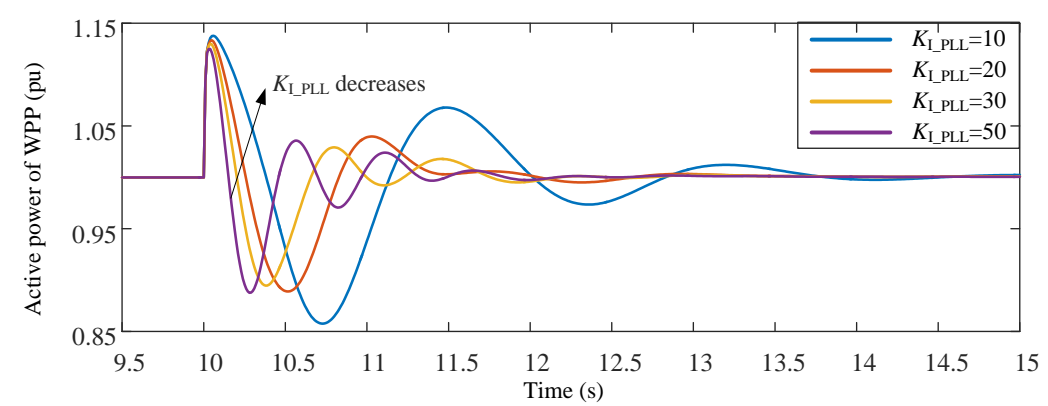

(a)

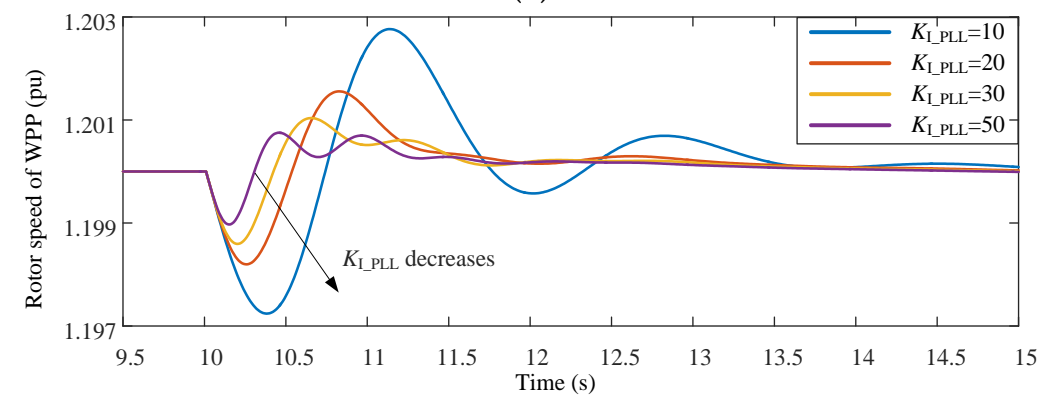

(b)

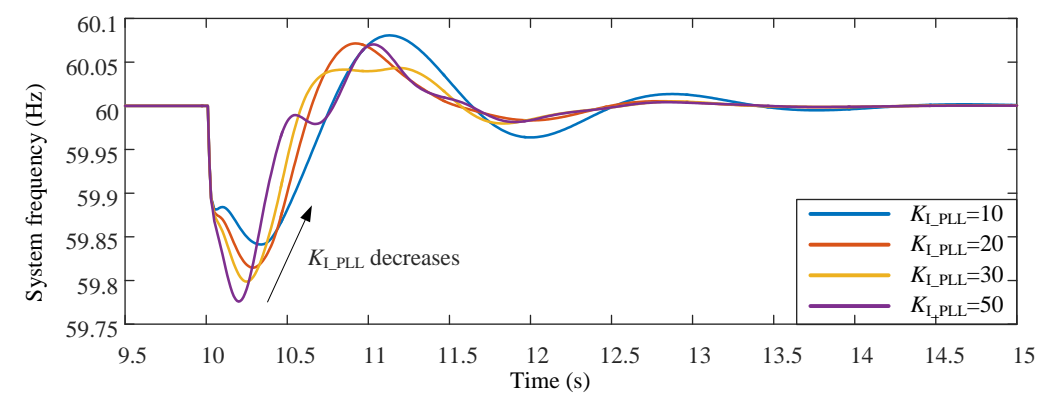

(c)

Figure 13. Case2: response curves of electrical quantities with different $K_{\mathrm{I} \_\mathrm{PLL}}\left(K_{\mathrm{P} \_\mathrm{PLL}}=4\right)$ under the disturbance of load reduction for inertia emulations: (a) Active power of the WPP; (b) Rotor speed deviation of the WPP; (c) System frequency.

To conclude, the inertia of the WPP is inversely proportional to $K_{I_{-} P L L}$ and $K_{\text {P_PLL }}$. The proportional gain and integral gain in PLL could be decreased simultaneously to improve the inertial response ability of the DFIG. The time domain simulation has the same results as that of the theoretical analysis in Section 2.2.

From case 3 to case5, the impacts of $K_{P_{-} P L L}$ and $K_{I_{-} P L L}$ on small signal stability of the system are studied. Considering that the electrical quantities in the same case have similar damping properties, the time domain waveforms of the active power of the WPP are employed to illustrate the damping properties of the system.

In case3, $K_{I_{-} P L L}$ is set as 100 , and $K_{P_{-} P L L}$ is set as $10,20,30$, and 40 , respectively. Figure 14 shows the oscillation curves of the active power of the WPP with different values of $K_{P_{-} P L L}$. The active power 
of the WPP fluctuate more intensely and spends longer time recovering from oscillation state to steady state with smaller $K_{P_{-} P L L}$. Therefore, the system damping is weakened with the decrease of $K_{P_{-} P L L}$. This result illustrates that the proportional gain in PLL cannot be set too small and the inertial response ability of the DFIG has an upper limit constrained by system stability.

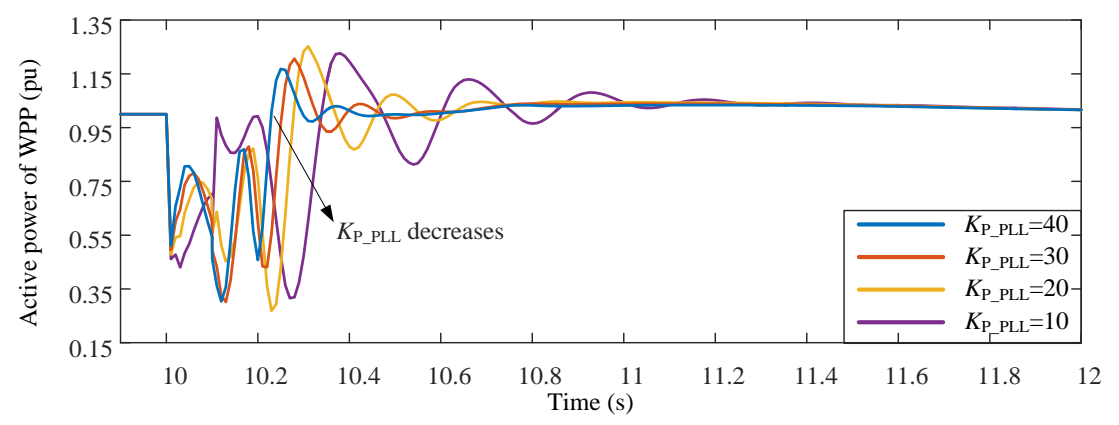

Figure 14. Case3: active power of the WPP with different $K_{P \_P L L}\left(K_{I}\right.$ PLL $\left.=100\right)$ for damping analysis.

In case4, $K_{P \_P L L}$ is set as 1 , and $K_{\text {I_PLL }}$ is set as $100,200,300$, and 400, respectively. Figure 15 shows the oscillation curves of the active power of WPP with different values of $K_{\text {I_PLL }}$. As shown in Figure 15, the active power has larger oscillation amplitudes and longer transient time with larger values of $K_{I_{-} P L L}$. Further, larger $K_{I_{-}}$PLL contributes to larger oscillation frequency and lower damping of the system, which corresponds with the theoretical results in Figure 7. Therefore, the decrease of $K_{\text {I_PLL }}$ is beneficial to both damping and inertia provision of the system.

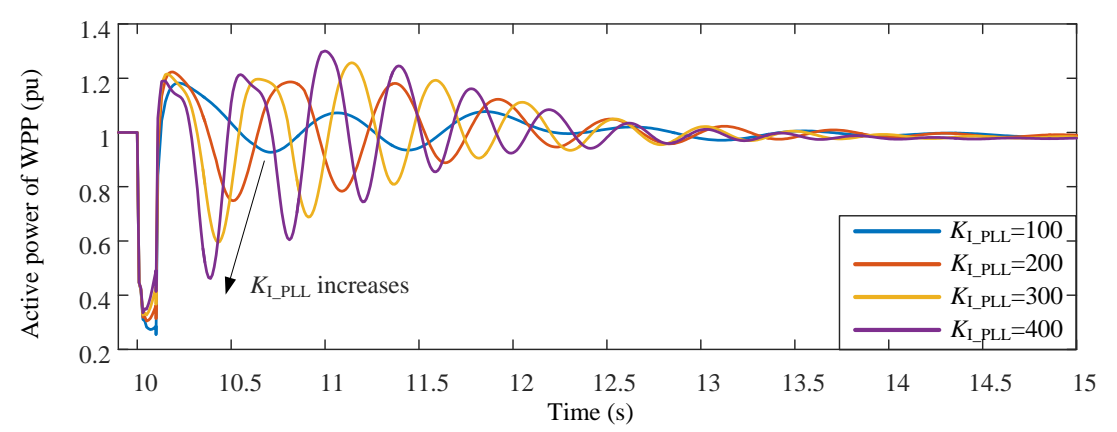

Figure 15. Case4: active power of the WPP with different $K_{I_{-} P L L}\left(K_{P_{-}}\right.$PLL $\left.=1\right)$ for damping analysis.

In case5, the ratio of $K_{I_{-} P L L}$ to $K_{P_{-} P L L}$ maintains constant: $k=2.5 . K_{I_{-} P L L} / K_{P_{-} P L L}$ are set as $100 / 40$, $50 / 20,12.5 / 5,6.25 / 2.5$, respectively. This case is conducted to verify that decreasing $K_{\text {I_PLL }}$ and $K_{\text {P_PLL }}$ with constant ratio $k$ would still deteriorate the system damping. Figure 16 shows the oscillation curves of the active power of the WPP with different $K_{I_{-} P L L}$ and $K_{P_{-} P L L}$. It is obvious that typical values of $K_{\text {I_PLL }}$ and $K_{\text {P_PLL }}(100,40)$ correspond with strong damping and quick recovery from oscillation to stability, whereas smaller $K_{I_{-} P L L}$ and $K_{P_{-} P L L}$ result in lower damping and even instability of the system.

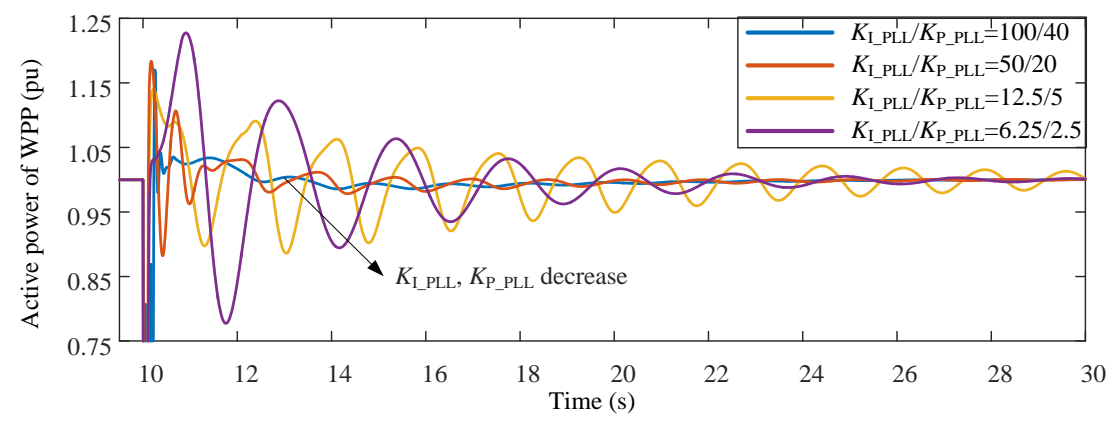

Figure 16. Case5: active power of the WPP with $K_{\mathrm{I} \_\mathrm{PLL}} / K_{\mathrm{P} \_\mathrm{PLL}}=2.5$ for damping analysis. 
The detailed inertia time constants of the WPP in case1-case2 and damping ratios in case3-case5 are described in Table 1.

Table 1. Inertia time constants in case1-case2 and damping ratios in case3-case5.

\begin{tabular}{ccccccccccc}
\hline \multicolumn{2}{c}{ Case1 } & \multicolumn{2}{c}{ Case2 } & \multicolumn{2}{c}{ Case3 } & \multicolumn{2}{c}{ Case4 } & \multicolumn{2}{c}{ Case5 } \\
\hline \multicolumn{2}{c}{$K_{\text {I_PLL }}=5$} & \multicolumn{2}{c}{$K_{\text {P_PLL }}=4$} & \multicolumn{2}{c}{$K_{\text {I_PLL }}=100$} & \multicolumn{2}{c}{$K_{\text {P_PLL }}=1$} & \multicolumn{2}{c}{$K_{\text {I_PLL }} / K_{\text {P_PLL }}=2.5$} \\
\hline$K_{\text {P_PLL }}$ & $H_{\mathrm{W}}(\mathrm{s})$ & $K_{\text {I_PLL }}$ & $H_{\mathrm{W}}(\mathrm{s})$ & $K_{\text {P_PLL }}$ & $\xi$ & $K_{\text {I_PLL }}$ & $\xi$ & $K_{\text {I_PLL }} / K_{\text {P_PLL }}$ & $\xi$ \\
\hline 6 & 0.6572 & 10 & 0.4929 & 10 & 0.1798 & 100 & 0.0868 & $100 / 40$ & 0.3139 \\
10 & 0.3942 & 20 & 0.2465 & 20 & 0.2387 & 200 & 0.0712 & $50 / 20$ & 0.3044 \\
15 & 0.2629 & 30 & 0.1643 & 30 & 0.2803 & 300 & 0.0675 & $12.5 / 5$ & 0.2603 \\
25 & 0.1577 & 50 & 0.0986 & 40 & 0.3139 & 400 & 0.0664 & $6.25 / 2.5$ & 0.1096 \\
\hline
\end{tabular}

The simulation results above verify that smaller $K_{I_{-} P L L}$ and $K_{P \_P L L}$ contribute to sufficient inertial response ability of the DFIG, whereas decrease the system damping instead. Aiming at this contradiction, $K_{P \_P L L}$ should be set a little larger, and $K_{\text {I_PLL }}$ should be set a little smaller following the three principles in Section 2.3.3. The parameters optimization is applied to the following actual NYPS-NETS power system.

\subsection{Simulations in NYPS-NETS Power System With WPPs Integration}

This section tests the effectiveness of parameters optimization of PLL on the inertial response ability of the WPP and the damping ratio in NYPS-NETS power system [36]. Figure 17 displays the network structure of NYPS-NETS power system, which consists of two areas: New York Power System and New England Test System. To meet rising demand for wind power penetration in the future system in 2024, three WPPs are integrated into the system, which contributes to $15 \%$ wind power penetration levels. Table 2 describes the locations and capacities of the three WPPs.

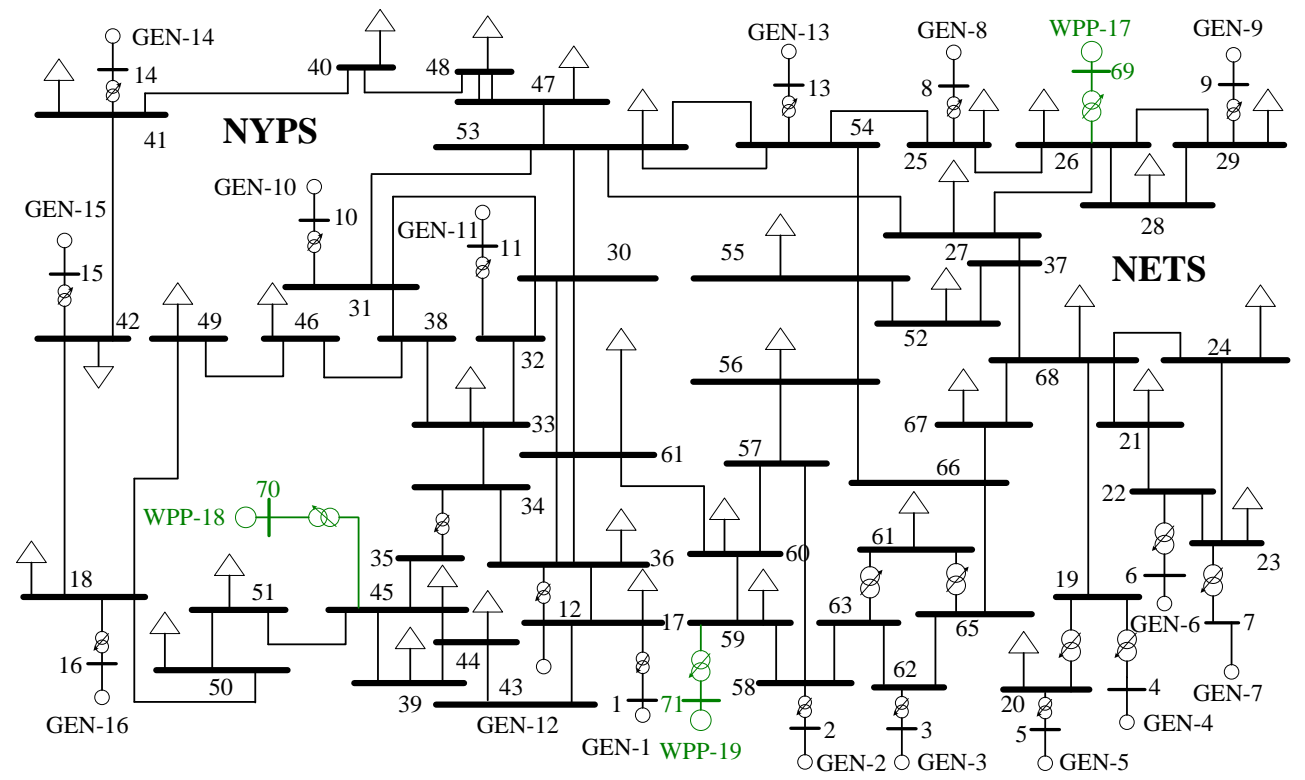

Figure 17. Schematic diagram of New York Power System and New England Test System (NYPS-NETS) power system with $15 \%$ wind power penetration level.

Table 2. Locations and capacities of wind power plants (WPPs).

\begin{tabular}{ccc}
\hline PCC & WPP-Number & Capacity \\
\hline Bus-69 & WPP-17 & 1110 MVA \\
Bus-45 & WPP-18 & 1110 MVA \\
Bus-59 & WPP-19 & 1110 MVA \\
\hline
\end{tabular}


The parameters in PLL are set as: (i) $K_{\text {I_PLL }} / K_{\text {P_PLL }}=100 / 40$ (Typical values); (ii) $K_{\text {I_PLL }} / K_{\text {P_PLL }}$ $=10 / 4$; (iii) $K_{I_{\perp} P L L} / K_{P_{-} P L L}=12 / 2.5$ (parameters optimization) to highlight the advantages of the proposed parameters optimization strategy. For comparing the inertial response ability under different parameters tuning of $K_{P_{-} P L L}$ and $K_{I_{-} P L L}, 500 \mathrm{MW}$ of active-load power is added on Bus-59 at $40 \mathrm{~s}$. The WPP-19 is taken as the observing object to reflect the performance of the system.

Figure 18a-c show the time domain waveforms of the active power of WPP-19, rotor speed of WPP-19, and the system frequency. When $K_{\text {P_PLL }}$ and $K_{\text {I_PLL }}$ are taken as the typical values (black curves), there are few inertial responses in WPP-19 after the frequency drop. The active power of WPP-19 fails to respond to the frequency deviations and has no contributions to the power imbalance of the system. The rotor speed of WPP-19 remains nearly unchanged, so there is no kinetic energy from the wind turbine rotor injected into the system. Consequently, the system frequency nadir reaches $59.85 \mathrm{~Hz}$. In contrast, if $K_{\mathrm{P} \_ \text {PLL }}$ and $K_{\mathrm{I}_{-} \mathrm{PLL}}$ are decreased to 4 and 10 with constant ratio: $K_{\mathrm{I} \_ \text {PLL }} / K_{\mathrm{P} \_ \text {PLL }}$ $=2.5$, the WPP-19 is provided with sufficient inertial response ability (blue dashed curves). The active power of WPP-19 increases to 12.3 p.u. at the initial stage of the disturbance, and declines gradually to release the kinetic energy from the wind turbine rotor. The inertial response of WPPs restrains the system frequency decline, so the system frequency nadir increases to $59.9 \mathrm{~Hz}$.

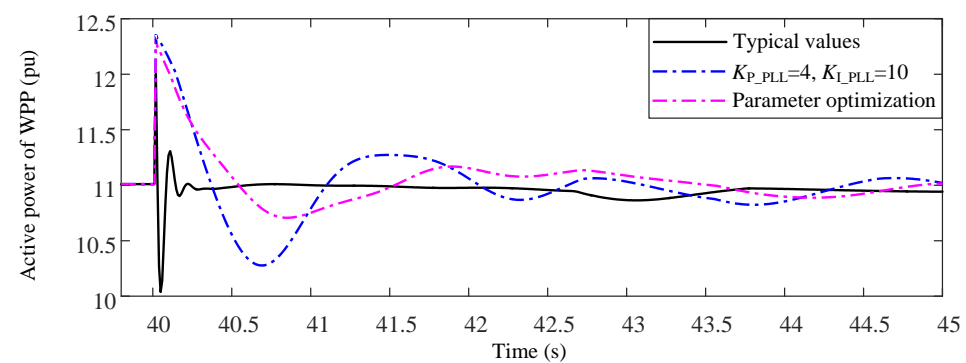

(a)

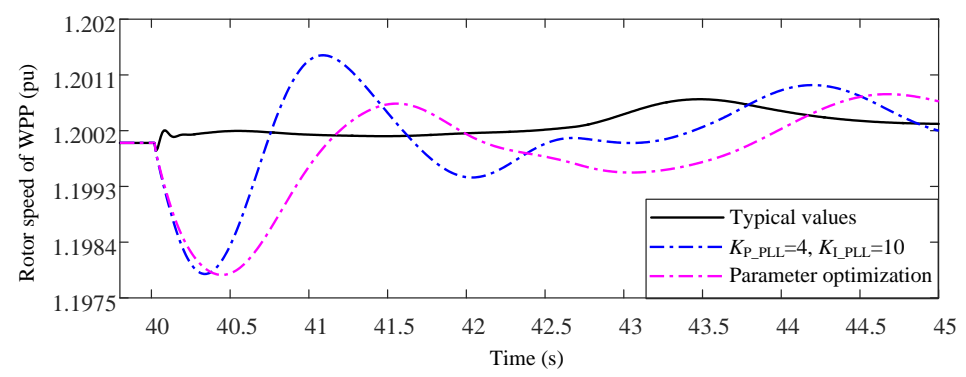

(b)

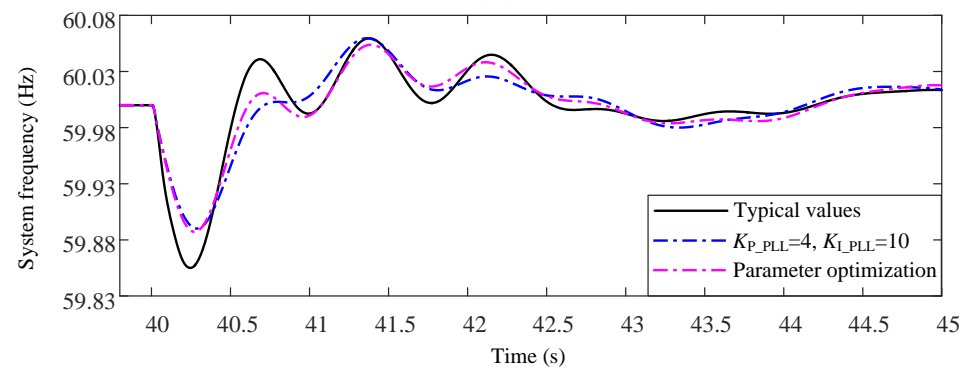

(c)

Figure 18. Response curves of electrical quantities in NYPS-NETS system with (i) $K_{\text {I_PLL }} / K_{\text {P_PLL }}$ $=100 / 40$ (Typical values); (ii) $K_{I_{-} P L L} / K_{P_{-} P L L}=10 / 4$; (iii) $K_{I_{\perp} P L L} / K_{P_{-} P L L}=12 / 2.5$ (parameters optimization) for inertia emulations: (a) Active power of WPP-19; (b) Rotor speed deviation of WPP-19; (c) System frequency.

The system damping under different parameters tuning of PLL is tested by adding a three-phase short circuit fault in line $25-26$ at $40 \mathrm{~s}$ and tripping the line after $0.1 \mathrm{~s}$. Figure 19 shows the oscillation 
curves of the active power of WPP-19. Comparing the black curve with the blue dashed curve in Figure 19, it indicates that decreasing $K_{I_{-} P L L}$ and $K_{P_{-} P L L}$ simultaneously deteriorates the system damping even if $K_{I_{-} P L L} / K_{P_{-} P L L}=$ constant. Focusing on this problem, the parameters in PLL are adjusted by increasing $K_{P_{-} P L L}$ and decreasing $K_{I_{\perp} P L L}$ based on the principles in Section 2.3.3. The proper PLL parameters adopted in this system are $K_{P_{-} P L L}=12, K_{I_{-} P L L}=2.5$. As is illustrated by the pink dashed curves in Figures 18 and 19, WPP-19 is provided with sufficient inertial response ability compared with $K_{\text {P_PLL }}=10, K_{I_{-} P L L}=4$. Meanwhile, the damping properties of the active power of WPP-19 is also enhanced and recover to the equal level of the typical-values condition $\left(K_{P_{-} P L L}=100\right.$, $\left.K_{\text {I_PLL }}=40\right)$.

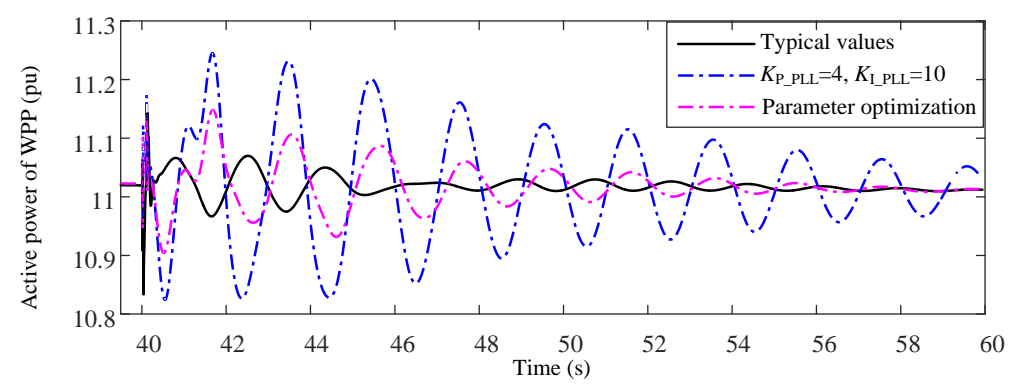

Figure 19. Active power of WPP-19 in NYPS-NETS system with (i) $K_{\text {I_PLL }} / K_{P \_P L L}=100 / 40$ (Typical values); (ii) $K_{\text {I_PLL }} / K_{\text {P_PLL }}=10 / 4$; (iii) $K_{\text {I_PLL }} / K_{\text {P_PLL }}=12 / 2.5$ (parameters optimization) for damping analysis.

Table 3 describes the inertia time constant of WPP-19 and the damping ratios of the dominant modes of the active power of WPP-19. After the parameters' optimization of PLL, WPP-19 is provided with larger inertia time constant (6.0243 s) and stronger damping properties (0.69) compared with the cases of typical values and decreasing $K_{I_{-} P L L}$ and $K_{\text {P_PLL }}$ with a constant ratio.

Table 3. Inertia time constants and damping ratios.

\begin{tabular}{ccc}
\hline $\boldsymbol{K}_{\mathbf{I} \_ \text {PLL}}, \boldsymbol{K}_{\mathbf{P} \_ \text {PLL }}$ & Inertia Constant & Damping Ratio \\
\hline 100,40 & $0.0452 \mathrm{~s}$ & 0.68 \\
10,4 & $4.8183 \mathrm{~s}$ & 0.33 \\
$12,2.5$ & $6.0243 \mathrm{~s}$ & 0.69 \\
\hline
\end{tabular}

\section{Discussion}

Based on the theoretical analysis and simulation results above, proper parameters tuning could increase both the inertial response ability of the DFIG and the small signal stability of the power system. The common research findings are obtained in [25] that decreasing the parameters in PLL with a constant ratio has no effects on the internal stability of PLL. However, this paper further illustrates that the small signal stability of the whole system is deteriorated under these parameters tuning. Consequently, the parameters optimization is proposed to solve the contradiction. Compared with [23], the inertia time constants calculated in this paper are the time-domain expressions, which could estimate precisely the inertial response ability of the certain wind farms. Based on the research results in [26,27], the paper not only clarifies the effects of $K_{I_{-} P L L}$ and $K_{P_{-} P L L}$ on the small signal stability of the power system but also investigates the internal relationship between the PLL and the inertia provision. Therefore, the synthetic effects of $K_{I_{L} P L L}$ and $K_{P_{-}}$PLL on inertia and damping are studied, respectively, in detail. The main innovation the paper is establishing the PLL-synchronized DFIG model, which imitates the motion of the SG and could give an all-around illustration for inertia and damping characteristics in the wind-integrated power system.

The current limitation of the paper is that the PLL-synchronized DFIG model only considers the dynamics of PLL and voltage-oriented control. The future research works will focus on establishing 
a more complex mathematical form of the model considering the dynamics of the inverter control and the driving chain. Referring to the power system stabilizer (PSS) in the traditional synchronous generator, the advanced damping controller for the PLL-based DFIG model could also be studied further for withstanding weak damping caused by higher penetration of renewable energy sources.

\section{Conclusions}

Aiming at reduced inertia and weak damping properties of the wind-integrated power system, this paper derives the synchronized swing equation of the DFIG based on the dynamic models of PLL. There is a similarity in mathematical form between the proposed swing equation and the rotor motion equation of the SG, which embodies the inertia constant, the damping coefficient, and the synchronizing torque. Thanks to this work, the inverter-based asynchronous wind generator is regarded as the SG, and the dynamic characteristics of the power system could be described by a series of synchronous motion equations. Then the inertia estimation of the DFIG and system damping analysis is conducted based on the PLL-synchronized swing equation. The conclusions are summarized as follows:

(i) The equivalent inertia of the DFIG is inversely proportional to both the proportional and integral gains of PLL. The proportional and integral gains should be small enough for providing the DFIG sufficient inertial response ability.

(ii) The internal stability of PLL will not change if the proportional and integral gains decrease with the constant ratio. Whereas aiming at the multi-machine system, decreasing the parameters in PLL with the constant ratio cannot avoid deteriorating the damping characteristics of the whole system. The small proportional gain will also slow down the response rate and locking accuracy of PLL.

(iii) The parameters optimization of PLL is proposed following three principles by decreasing the ratio of $K_{I_{-} P L L}$ to $K_{P \_P L L}$ for obtaining sufficient inertial response ability of the WPP and ideal damping properties of the system at the same.

Author Contributions: Conceptualization, Y.Y.; Formal analysis, Y.W.; Investigation, Y.Y.; Methodology, Y.W.; Supervision, Y.Y.; Validation, Y.W.; Writing-original draft, Y.W.

Funding: This work was supported by the National Support Program of China (\#2015BAG20B05), the Zhejiang Province Natural Science Foundation of China (\#LY14E070003), and the Independent Innovation Fund Project of Wuhan University of Technology (\#2017-JL-002).

Conflicts of Interest: The authors declare no conflict of interest.

\section{Appendix A}

The basic parameters for system models in Figures 1 and 6 are listed as follows:

\begin{tabular}{ccccccc}
\hline$i_{\mathrm{ds}}$ & $i_{\mathrm{qs}}$ & $s_{\mathrm{r}}$ & $K_{\mathrm{P} \_ \text {PLL }}$ & $K_{\mathrm{I} \_ \text {PLL }}$ & $M_{\mathrm{g}}$ & $\delta_{\mathrm{g}}$ \\
\hline 0.3122 & 0.95 & -0.2 & 40 & 100 & 0.0531 & $38.78^{\circ}$ \\
\hline$D_{\mathrm{g}}$ & $U_{\mathrm{w}}$ & $E$ & $U$ & $X_{1}$ & $X_{2}$ & $\delta_{\mathrm{w}}$ \\
\hline 0.001 & 0.998 & 0.995 & 1.000 & 0.1 & 0.3 & $33.99^{\circ}$ \\
\hline
\end{tabular}

\section{References}

1. Islam, M.R.; Guo, Y.; Zhu, J.G. A review of offshore wind turbine nacelle: Technical challenges, and research and developmental trends. Renew. Sustain. Energy Rev. 2014, 3, 161-176. [CrossRef]

2. Global Wind Energy Council. "Global Wind Report-Annual market update 2017". Available online: http://files.gwec.net/register?file=/files/GWR2017.pdf (accessed on 5 April 2018).

3. Yuan, T.J.; Wang, J.J.; Guan, Y.H.; Liu, Z.; Song, X.F.; Che, Y.; Cao, W.P. Virtual inertia adaptive control of a doubly fed induction generator wind power system with hydrogen energy storage. Energies 2018, 11, 904. [CrossRef] 
4. Xiong, L.S.; Li, Y.J.; Zhu, Y.X.; Yang, P.; Xu, Z.R. Coordinated Control Schemes of Super-Capacitor and Kinetic Energy of DFIG for System Frequency Support. Energies 2018, 11, 103. [CrossRef]

5. Ma, Y.F.; Liu, J.; Liu, H.H.; Zhao, S.Q. Active-Reactive Additional Damping Control of a Doubly-Fed Induction Generator Based on Active Disturbance Rejection Control. Energies 2018, 11, 1314. [CrossRef]

6. Shahid, K.; Altin, M.; Mikkelsen, L.M.; Olsen, R.L.; Lov, F. ICT Based Performance Evaluation of Primary Frequency Control Support from Renewable Power Plants in Smart Grids. Energies 2018, 11, 1329. [CrossRef]

7. Islam, M.R.; Guo, Y.; Zhu, J.G. Steady state characteristic simulation of DFIG for wind power system. In Proceedings of the International Conference on Electrical \& Computer Engineering, Bursa, Turkey, 2-5 December 2010.

8. Beltran, O.; Pena, R.; Segundo, J.; Esparza, A.; Muljadi, E.; Wenzhong, D. Inertia Estimation of Wind Power Plants Based on the Swing Equation and Phasor Measurement Units. Appl. Sci. 2018, 8, 2413. [CrossRef]

9. Tang, Y.; Dai, J.F.; Ning, J.; Dang, J.; Li, Y.; Tian, X.S. An Extended System Frequency Response Model Considering Wind Power Participation in Frequency Regulation. Energies 2018, 10, 1797. [CrossRef]

10. Cheng, W.H.; Teng, Z.X.; Zhao, J.H.; Qiu, J. Small-Signal Performance of Type 4 Wind Turbine Generator-Based Clusters in Power Systems. Energies 2018, 11, 1486. [CrossRef]

11. Xu, Y.; Wen, F.S.; Zhao, H.W.; Chen, M.H.; Yang, Z.; Shang, H.Y. Stochastic Small Signal Stability of a Power System with Uncertainties. Energies 2018, 11, 2980. [CrossRef]

12. Tamrakar, U.; Shrestha, D.; Maharjan, M.; Bhattarai, B.P.; Hansen, T.M.; Tonkoski, R. Virtual Inertia: Current Trends and Future Directions. Appl. Sci. 2017, 7, 654. [CrossRef]

13. Hwang, M.; Muljadi, E.; Park, J.W.; Sorensen, P.; Kang, Y.C. Dynamic droop-based inertial control of a doubly-fed induction generator. IEEE Trans. Power Syst. 2016, 7, 924-933. [CrossRef]

14. Kerdphol, T.; Rahman, F.S.; Mitani, Y. Virtual Inertia Control Application to Enhance Frequency Stability of Interconnected Power Systems with High Renewable Energy Penetration. Energies 2018, 11, 981. [CrossRef]

15. Morren, J.; Haan, S.W.H.D.; Kling, W.L.; Ferreira, J.A. Wind turbines emulating inertia and supporting primary frequency control. IEEE Trans. Power Syst. 2006, 21, 433-434. [CrossRef]

16. Wang, Y.; Meng, J.; Zhang, X.; Xu, L. Control of PMSG-based wind turbines for system inertial response and power oscillation damping. IEEE Trans. Energy Convers. 2015, 6, 565-574. [CrossRef]

17. Musarrat, M.N.; Islam, M.R.; Muttaqi, K.M.; Sutanto, D. Enhanced Frequency Support From a PMSG-Based Wind Energy Conversion System Integrated with a High Temperature SMES in Standalone Power Supply Systems. IEEE Trans. Appl. Supercond. 2019, 29, 3800206. [CrossRef]

18. Gautam, D.; Vittal, V. Impact of DFIG based Wind Turbine Generators on Transient and Small Signal Stability of Power Systems. IEEE Trans. Power Syst. 2010, 24, 1426-1434. [CrossRef]

19. Zhang, X.; Fu, Y.; Wang, S.; Wang, Y. Effects of two-area variable inertia on transient stabilization in interconnected power system with DFIG-based wind turbines. IET Renew. Power Gen. 2017, 11, 696-706. [CrossRef]

20. Zhong, Q.C. Virtual Synchronous Machines: A unified interface for grid integration. IEEE Power Electron. Mag. 2016, 3, 18-27. [CrossRef]

21. Wu, H.; Ruan, X.; Yang, D.S.; Chen, X.R.; Zhao, W.X.; Lv, Z.P.; Zhong, Q.C. Small-Signal Modeling and Parameters Design for Virtual Synchronous Generators. IEEE Trans. Ind. Electron. 2016, 63, 4292-4303. [CrossRef]

22. Khan, S.; Bletterie, B.; Anta, A.; Gawlik, W. On Small Signal Frequency Stability under Virtual Inertia and the Role of PLLs. Energies 2018, 11, 2372. [CrossRef]

23. He, W.; Yuan, X.; Hu, J. Inertia Provision and Estimation of PLL-based DFIG Wind Turbines. IEEE Trans. Power Syst. 2016, 32, 510-521. [CrossRef]

24. Hu, J.; Sun, L.; Yuan, X.M.; Wang, S. Modeling of Type 3 Wind Turbine with df/dt Inertia Control for System Frequency Response Study. IEEE Trans. Power Syst. 2017, 32, 2799-2809. [CrossRef]

25. Hu, J.; Wang, S.; Tang, W.; Xiong, X. Full-capacity wind turbine with inertial support by adjusting phase-locked loop response. IET Renew. Power Gen. 2016, 11, 44-53. [CrossRef]

26. Ma, J.; Qiu, Y.; Li, Y.; Zhao, W.; Song, Z.; Thorp, J.S. Research on the impact of WTG virtual inertia control on power system small-signal stability considering the phase-locked loop. IEEE Trans. Power Syst. 2017, 32, 20942105.

27. Tan, S.; Geng, H.; Yang, G. Philips-Heffron model for current-controlled power electronic generation unit. J. Mod. Power Syst. Clean Energy. 2017, 6, 1-13. 
28. Wu, F.; Zhang, X.P.; Godfrey, K.; Ju, P. Small signal stability analysis and optimal control of a wind turbine with doubly fed induction generator. IET Gener. Transm. Dis. 2007, 1, 751-760. [CrossRef]

29. Power Technologies International. PSS/E-33.4 Program Application Guide. 2013, Volume 2. Available online: https: / / www.scribd.com/document/241950119/POM-PSSE33-pdf (accessed on 6 March 2019).

30. Zhong, Q.C.; Nguyen, P.L. Sinusoid-locked loops to detect the frequency, the amplitude and the phase of the fundamental component of a periodic signal. In Proceedings of the 24th Conference Control and Decision Conference (CCDC), Taiyuan, China, 2012.

31. Wang, Z.W.; Shen, C.; Liu, F. Impact of DFIG with Phase Lock Loop Dynamics on Power Systems Small Signal Stability. In Proceedings of the Pes General Meeting, Conference \& Exposition IEEE, Washington, DC, USA, 27-31 July 2014.

32. Abad, G.; Jesús, L.; Rodriguez, M.A.; Marroyo, L.; Iwanski, G. Doubly Fed Induction Machine: Modeling and Control for Wind Energy Generation; Wiley IEEE Press: Hoboken, NJ, USA, 2011.

33. Anderson, P.M. Power System Control and Stability, 2nd ed.; Iowa State University Press: Ames, IA, USA, 1977; 40p.

34. Gautam, D.; Goel, L.; Ayyanar, R.; Vittal, V.; Harbour, T. Control strategy to mitigate the impact of reduced inertia due to doubly fed induction generators on large power systems. IEEE Trans. Power Syst. 2011, 26, 214-224. [CrossRef]

35. Mei, X.R.; Zhuang, X.Y. Principle of Automatic Control, 2nd ed.; Science Press: Beijing, China, 2007; pp. 58-71.

36. Singh, A.K.; Pal, B.C. IEEE PES Task Force on Benchmark Systems for Stability Controls Report on the 68-Bus, 16-Machine, 5-Area System. Available online: http:/ / www.sel.eesc.usp.br/ieee/. (accessed on 1 August 2015).

(C) 2019 by the authors. Licensee MDPI, Basel, Switzerland. This article is an open access article distributed under the terms and conditions of the Creative Commons Attribution (CC BY) license (http:// creativecommons.org/licenses/by/4.0/). 